\title{
DISTRIBUIÇÃO NO TEMPO GEOLÓGICO DOS PRINCIPAIS DEPÓSITOS MINERAIS BRASILEIROS: 1. CADASTRO DOS MODELOS GENÉTICOS E IDADES DOS DEPÓSITOS
}

\author{
JOÃO CARLOS BIONDI*
}

\begin{abstract}
TIME DISTRIBUTION OF THE MAIN BRAZILIAN MINERAL DEPOSITS: 1 GENETIC MODELS AND AGES The knowledge of mineral deposits time partition is an important prospection guide because when restricted to a given epoch, mineral deposits concentrate within one geological unit. In this paper a file with informations about the 194 main brazilian mineral deposits is shown. These deposits were selected mainly by their economic significance, to point out metalogenic processes active during a certain epoch and by their prospective significance as indicators of potential for mineral deposits of the same type, in one region or geological unit. The file contains data about (1) ore composition, (2) deposit name and location, (3) probable genetic model, (4) age of mineralization and (5) references. In the second part of this work these mineral deposits will be grouped and each deposit will be located on geological time accordingly their ore ages. Epochs when groups of mineral deposit formed will be compared with the main brazilian thermo-tectonic events.

Kewywords: Brasilian mineral deposits, genetic models, ages of deposits

RESUMO O conhecimento da distribuição dos depósitos minerais no tempo geológico é um importante guia de prospecção, pois quando restritos a uma determinada época, os depósitos tendem a se concentrar em uma unidade geológica. Nesse artigo é mostrado um banco de dados com informações sobre 194 depósitos minerais brasileiros. Esses depósitos foram selecionados pelas suas importâncias econômicas, por representarem processos metalogenéticos ativos em uma dada época e pelos seus significados prospectivos, como indicadores da potencialidade das regiões ou unidades geológicas onde ocorrem. Nesse banco de dados constam as seguintes informações: (1) minério, (2) nome e localização do depósito, (3) modelo genético provável, (4) idade da mineralização e (5) referências bibliográficas. Na segunda parte desse trabalho esses depósitos serão agrupados e os depósitos de cada um desses grupos serão situados no tempo geológico conforme as idades das suas mineralizações. As épocas nas quais formaram-se esses depósitos serão comparadas às épocas dos principais eventos termo-tectônicos brasileiros.

Palavras-chaves: depósitos minerais brasileiros, modelos genéticos, idades dos depósitos
\end{abstract}

INTRODUÇÃO Os processos mineralizadores variaram nos últimos 3000 Ma condicionados pelas mudanças ocorridas na crosta terrestre e na superficie da litosfera. As grandes variações nos processos resultaram em várias mudanças nos tipos de depósitos gerados ao longo do tempo. Algumas épocas geológicas se caracterizaram por ambientes geológicos especialmente favoráveis ao desenvolvimento de um ou alguns processos geológicos específicos, capazes de gerar tipos específicos de depósitos minerais. Desse modo formaram-se agrupamentos de depósitos, concentrados em um ou alguns períodos relativamente restritos da história da litosfera. As concentrações primárias de diamantes em kimberlitos e os depósitos vulcanogênicos com sulfetos de $\mathrm{Cu}, \mathrm{Pb}, \mathrm{Zn}$ tipo Kuroko são exemplos conhecidos, entre muitos outros, de tipos de depósitos que se concentram em determinadas épocas geológicas.

Alguns tipos de depósitos, cujas géneses são influenciadas por fenômenos globais, concentram-se, em todo o globo, em períodos geológicos restritos, como exemplificam as formações ferríferas bandadas gigantes do tipo Superior, cujas idades na maior parte das vezes variam entre 1800 e $2000 \mathrm{Ma}$. Nesse caso, a explicação reside em que nesse período ocorreu uma mudança global na composição da atmosfera, devida a um aumento importante na razão O2/CO2. Em outros casos, os depósitos formam-se como consequências de eventos tectônicos regionais, como uma subducção, e concentram-se em uma dada região em uma determinada época ou período geológico. Em todos os casos, o conhecimento da distribuição dos depósitos minerais no tempo geológico é importante como guia de prospecção. Quando restritos a uma determinada época, os depósitos concentram-se também em uma unidade geológica e, como consequência, em uma região restrita, onde essa unidade aflorar. Isto toma o conhecimento da distribuição dos depósitos minerais no tempo geológico uma informação necessária à prospecção mineral.

Devido unicamente as limitações de espaço da Revista Brasileira de Geociências esse trabalho será dividido em duas partes. Nessa primeira parte será mostrado o banco de dados com as informações sobre os depósitos minerais brasileiros que serão utilizadas para discutir a distribuição no tempo desses depósitos minerais. Na segunda parte, os depósitos minerais serão distribuídos no tempo geológico conforme as idades de suas mineralizações.

PROCEDIMENTOS ADOTADOS A tabela 1 lista 194 depósitos minerais brasileiros organizados alfabeticamente segundo o nome da principal substância ou elemento do minério. Esses depósitos foram selecionados principalmente pelas suas importâncias económicas, mas também pela importância que têm para a compreensão dos processos metalogenéticos ativos em uma dada época e pelas suas importâncias prospectivas, como indicadores da potencialidade da região ou unidade geológica. Nessa tabela constam as seguintes informações:

- Minério: Os principais elementos ou substâncias de interesse econômico que constituem o minério.

- Nome e localização do depósito

- Modelo genético provável: Na maior parte das vezes esta informação foi obtida da literatura. Quando não mencionado na literatura, o modelo foi deduzido da descrição do depósito e do ambiente geológico no qual está situado.

- Idade da mineralização: Obtida da literatura. Os procedimentos adotados para selecionar e categorizar as idades das mineralizações serão discutidos a seguir.

- Referências bibliográficas: Trabalhos de onde foram obtidas as informações que constam na tabela. Quando se discutir um depósito qualquer da tabela 1 deve ser compreendido que as informações são provenientes dessas referências, caso contrário será citada a referência específica sobre $\mathrm{o}$ assunto tratado no texto. Informações sobre o conteúdo original do depósito e idades das encaixantes foram também cadastradas e estão disponíveis contra requisição ao autor.

CRITÉRIOS PARA CATEGORIZAR AS IDADES DOS DEPÓSITOS MINERAIS Geralmente os minérios não podem ser datados diretamente ou porque seus constituintes minerais não contêm isótopos radiogênicos ou a técnica de datação não está ainda otimizada (caso do Re-Os para datar minérios com ouro). Vários depósitos têm minérios com substâncias radiogênicas, mas a interpretação dos resultados analíticos é complexa e exige informações geológicas e geoquímicas nem sempre disponíveis, como no método $\mathrm{Pb}-\mathrm{Pb}$. Em todos os casos, a determinação direta ou indireta da idade absoluta do minério exige sempre um conhecimento muito bom dos processos mineralizadores, que informarão sobre a procedência e a origem dos isótopos usados nas datações. Na maioria dos casos a impossibilidade de datar diretamente os minérios implica em interpretar as idades das mineralizações a partir de datações das rochas do depósito, das rochas regionais e/ou da análise de uma série de dados geológicos e geoquímicos que indicam a relação temporal entre as unidades geológicas que constituem ou se relacionam ao depósito. Devido a essas dificuldades, as idades das mineralizações mostradas na tabela foram, visando as discussões a serem feitas, separadas em três grupos:

1. Idade provável: Nessa categoria foram enquadradas as idades, ou intervalo de idades, de mineralizações de depósitos minerais cujos processos mineralizadores (dos quais os modelos genéticos são derivados) são conhecidos, definidos por meio da datação direta de um dos minerais de minério ou da ganga ou por correlação com um fenómeno geológico de idade conhecida. Como exemplo podem ser citadas as 
Tabela l-Modelos genéticos e idades dos principais depósitos minerais brasileiros, excluídos carvão, turfa, petróleo, rochas ornamentais e calcário, indexados por ordem alfabética do principal elemento ou substância do minério.

\begin{tabular}{|c|c|c|c|c|}
\hline MINÉRIO & $\begin{array}{c}\text { NOME DO } \\
\text { DEPOSITO } \\
\text { (Estado) }\end{array}$ & $\begin{array}{l}\text { MODELO GENÉTICO } \\
\text { PROVAVEL }\end{array}$ & $\begin{array}{c}\text { DADE DA MINERALZAÇĀO } \\
\text { (Min - Max) } \\
(\text { Ma) } \\
\end{array}$ & REFERÊNCIA \\
\hline $\begin{array}{l}\text { Água } \\
\text { marinha }\end{array}$ & ltambé (BA) & Pegmatito & $500-550(\mathrm{p})$ & Silva \& Silva 1981 \\
\hline $\begin{array}{l}\text { Água } \\
\text { marinha }\end{array}$ & Tenente Ananias (RN) & Pegmatito & $500-550(\mathrm{p})$ & do Rêgo 1981 \\
\hline Al & $\begin{array}{l}\text { Conjunto de depósitos da regiāo } \\
\text { de Poços de Caldas (MG) }\end{array}$ & Bauxitas residuais & $25-40(P)$ & Parisi 1988 \\
\hline $\mathrm{Al}$ & Morro Redondo (RJ) & Bauxitas residuats & $50-55(\mathrm{P})$ & Parisi 1988 \\
\hline$\overline{\mathrm{Al}}$ & $\begin{array}{l}\text { Conjunto de depósitos da Zona } \\
\text { da Mata (MG) }\end{array}$ & Bauxitas residuais & $\begin{array}{c}2-11(P) \\
40-55(P)\end{array}$ & Lopes \& Branquinho 1988 \\
\hline$\overline{\mathrm{Al}}$ & Paru, Jari (AM) & Bauxitas residuais & $2-11(\mathrm{P})$ & Braga \& Silva Alves 1988 \\
\hline$\overline{\mathrm{Al}}$ & Porto Trombetas (PA) & Bauxitas residuais & $11-55(\mathrm{P})$ & Hernalsteens \& Lapa 1988 \\
\hline$\overline{A l}$ & Paragomi-nas(PA) & Bauxitas residuais & $2-55(\mathrm{P})$ & Braga \& Silva Alves 1988 \\
\hline $\mathrm{Al}$ & Almeirim-Mazagão (PA) & Bauxitas residuais & $2-55(\mathrm{P})$ & Braga \& Silva Alves 1988 \\
\hline $\mathrm{Al}, \mathrm{Fe}$ & Jatapu (AM) & Bauxitas e lateritas & $2-11(\mathrm{P})$ & Kotschoubey 1988 \\
\hline $\begin{array}{l}\text { Ametista, } \\
\text { ágata }\end{array}$ & Alto Uruguai (RS) & $\begin{array}{l}\text { Assimilação de sílica em lavas } \\
\text { básicas }\end{array}$ & $100-110(\mathrm{P})$ & $\begin{array}{l}\text { Schmitt et al. 1981. Cassedane } \\
\& \text { Sauer 1988, Junchen et al. } \\
1990\end{array}$ \\
\hline Ametista & Alto Bonito (PA) & $\begin{array}{l}\text { Zona de cisalhamento em } \\
\text { quartzitos }\end{array}$ & $2551-2573(\mathrm{p})$ & \begin{tabular}{|lll} 
Collyer, \& Mártires \\
1981.Collyer \& Mártires & 1986 \\
\end{tabular} \\
\hline Ametista & Pau D'Arco (PA) & Coluvial e aluvial & $<1(\mathrm{P})$ & $\begin{array}{l}\text { Collyer et al. 1981.Cassedane } \\
\& \text { Sauer 1988, Collyer et al. } \\
1990\end{array}$ \\
\hline Asbesto & Minaçu, Canabrava (GO) & $\begin{array}{l}\text { Metamorfismo sobre rochas } \\
\text { ultrabásicas (komatiitos?) }\end{array}$ & $\begin{array}{l}1800-2000 \text { (I) ou } \\
1000-1100 \text { (I) }\end{array}$ & \\
\hline $\mathrm{Au}$ & Passagem de Mariana (MG) & $\begin{array}{l}\text { Năo definido } \\
\text { (Turmalinitos, dolomitos em } \\
\text { filós em zonas de cisalhamento) }\end{array}$ & $\begin{array}{c}2067-2093 \\
\text { (U-Pb em monazitas dos filōes) (P) }\end{array}$ & $\begin{array}{l}\text { Schrank \& Machado 1996 a. } \\
\text { Ladeira 1988. }\end{array}$ \\
\hline $\mathrm{Au}(\mathrm{Ag})$ & Morro Velho (MG) & $\begin{array}{l}\text { Sedimentar química de } \\
\text { derivação vulcânica (BIF. } \\
\text { Chert), estratiforme. Filōes } \\
\text { originados por remobilização } \\
\text { metamórfica. } \\
\end{array}$ & $\begin{array}{c}\text { Evento Rio das Velhas }=2772-2780 \\
\text { (P) } \\
\text { Riolitos }=2883 \pm 6(\mathrm{P}) \\
\text { Zircão detrítico }=2278 ?\end{array}$ & $\begin{array}{l}\text { Schrank \& Machado 1996 a. } \\
\text { Machado et al. 1996, Tassinari } \\
\text { \& Mellito 1994. Ladeira 1988. }\end{array}$ \\
\hline$\overline{\mathrm{Au}}$ & Raposos, Faria (MG) & $\begin{array}{l}\text { Sedimentar química de } \\
\text { derivaçăo vulcânica (BIF, } \\
\text { Chert), estratiforme. Filōes } \\
\text { originados por remobilização } \\
\text { metamórfica. }\end{array}$ & $\begin{array}{c}\text { Evento Rio das Velhas }=2772-2780 \\
\text { (P) } \\
\text { Riolitos }=2883 \pm 6(\mathrm{P}) \\
\text { Zircão detrítico }=2278 ?\end{array}$ & $\begin{array}{l}\text { Schrank \& Machado 1996 a } \\
\text { Machado et al. 1996. Tassinari } \\
\text { \& Mellito 1994. Ladeira 1988. }\end{array}$ \\
\hline $\begin{array}{l}\mathrm{Au}(\mathrm{Cu}, \mathrm{Pb}, \\
\mathrm{Ag})\end{array}$ & Cuiabá, Carrapato (MG) & $\begin{array}{l}\text { Sedimentar química de } \\
\text { derivação vulcânica (BIF, } \\
\text { Chern), estratiforme. Filő́es } \\
\text { originados por remobilização } \\
\text { metamórfica. }\end{array}$ & $\begin{array}{c}\text { Evento Rio das Velhas }=2772-2780 \\
\text { (P) } \\
\text { Riolitos }=2883 \pm 6(\mathrm{P}) \\
\text { Zircào detrítico }=2278 ?\end{array}$ & $\begin{array}{l}\text { Schrank \& Machado } 1996 \text { b. } \\
\text { Machado et al. 1996, Tassinari } \\
\text { \& Mellito 1994. Ladeira, } 1988 .\end{array}$ \\
\hline $\overrightarrow{\mathrm{Au}}$ & Săo Bento (MG) & $\begin{array}{l}\text { Sedimentar química de } \\
\text { derivação vulcânica (BIF, } \\
\text { Chert), estratiforme, Filōes } \\
\text { originados por remobilizaçăo } \\
\text { metamórfica. }\end{array}$ & $\begin{array}{c}\text { Evento Rio das Velhas }=2772-2780 \\
\text { (P) } \\
\text { Riolitos }=2883 \pm 6(\mathrm{P}) \\
\text { Zircão detrítico }=2278 ?\end{array}$ & $\begin{array}{l}\text { Schrank \& Machado } 1996 \\
\text { Machado et al. 1996. Tassinari } \\
\text { \& Mellito 1994. Ladeira 1988. }\end{array}$ \\
\hline $\mathrm{Au}$ & Morro do Ouro, Paracatu (MG) & $\begin{array}{l}\text { Carlin (?). Ouro de granulação } \\
\text { fina, com baixo teor, em } \\
\text { metapelitos negros. }\end{array}$ & $\begin{array}{l}\text { 1000-1200 (p) (deposiçăo) } \\
650-680 \text { (remobilizaçăo) }\end{array}$ & $\begin{array}{ll}\text { Zini ef al. 1988. Tassinari } & \& \\
\text { Mellito 1994, Freitas-Silva } & \& \\
\text { Dardenne 1997 } & \\
\text { Darde } & \end{array}$ \\
\hline $\mathrm{Au}$ & Mina III, Meia Pataca (GO) & $\begin{array}{l}\text { Sedimentar química de } \\
\text { derivação vulcânica (BIF, } \\
\text { Chert),estratiforme (greenstone } \\
\text { belt). Remobilização } \\
\text { metamórfica }\end{array}$ & $\begin{array}{c}2900(1) \text { (deposição) } \\
500-550 \text { (remobilizaçáo) }\end{array}$ & $\begin{array}{l}\text { Yamaoka \& Araujo } 1988 . \\
\text { Tassinari \& Mellito } 1994, \\
\text { Fortes } 1997 . \text { Fortes et al. } 1995\end{array}$ \\
\hline Au & Meia Pataca (GO) & $\begin{array}{l}\text { Sedimentar química de } \\
\text { derivaçăo vulcânica (BIF, } \\
\text { Chert), estratiforme (greenstone } \\
\text { belt). Remobilização em zona de } \\
\text { cisalhamento }\end{array}$ & $\begin{array}{c}2900(\mathrm{D}) \text { (deposition) } \\
500-550 \text { (p) (remobilização) }\end{array}$ & $\begin{array}{l}\text { Magalhảes et al. 1988. Tassinari } \\
\text { \& Mellito 1994, Fortes } 1997 . \\
\text { Fortes et al. } 1995\end{array}$ \\
\hline$\dot{A u}$ & Jacobina (BA) & Paleoplacer-tipo Witwatersrand & $1900-2080$ (P) (U-Pb) & $\begin{array}{l}\text { Molinari \& Scarpelli, } 1988 . \\
\text { Mougeot et al. } 1996\end{array}$ \\
\hline
\end{tabular}


Tabela l-Continuação

\begin{tabular}{|c|c|c|c|c|}
\hline MINERRIO & $\begin{array}{c}\text { NOME DO } \\
\text { DEPOSITO } \\
\text { (Estado) }\end{array}$ & $\begin{array}{l}\text { MODELO GENÉTICO } \\
\text { PROVAVEL }\end{array}$ & $\begin{array}{c}\text { IDADE DA MINERALUZAÇÃO } \\
\text { (Min - Max) } \\
(\mathrm{Ma})\end{array}$ & REFERÊNCLA \\
\hline $\mathrm{Au}$ & São Francisco (RN) & $\begin{array}{l}\text { Sedimentar química de } \\
\text { derivação vulcânica (BIF, } \\
\text { Chert), estrati-forme. } \\
\text { Remobilização metamórfica. }\end{array}$ & $\begin{array}{c}1500-1700(I) \text { (deposição) } \\
650(\text { P) (remobilização) }\end{array}$ & $\begin{array}{l}\text { de Ferran 1988. Tassinari } \\
\text { Mellito } 1994\end{array}$ \\
\hline $\mathrm{Au}$ & Cabaçal I (MT) & Zona de cisalhamento & $\begin{array}{r}1750-1900(\mathrm{p}) \\
\text { (Pb-Pb-galena) }\end{array}$ & $\begin{array}{l}\text { Monteiro et al. 1988. Tassinari } \\
\text { \& Mellito } 1994\end{array}$ \\
\hline $\begin{array}{l}\text { Au (Pd, } \\
\text { Ag) }\end{array}$ & $\begin{array}{l}\text { Conjunto de depósitos Rio } \\
\text { Madeira (RO) }\end{array}$ & Placer fluvial & $<1(\mathrm{P})$ & Bastos 1988 \\
\hline Au & Salaman-gone, Mutum (AP) & $\begin{array}{l}\text { Veios de quartzo em zona de } \\
\text { cisalhamento (?) }\end{array}$ & $2600-2900$ (I) & $\begin{array}{l}\text { de Ferran } 1988 \\
\text { Tassinari \& Mellito } 1994\end{array}$ \\
\hline $\begin{array}{l}\mathrm{Au}, \mathrm{Pd} \\
(\mathrm{Ag})\end{array}$ & Serra Pelada (PA) & $\begin{array}{l}\text { Front de oxidação em } \\
\text { metassedimentos clásticos. } \\
\text { Hidrotermalismo em zona de } \\
\text { cisalhamento. }\end{array}$ & $\begin{array}{l}2708-2778 \text { (I) } \\
\text { (U-Pb em zircão) }\end{array}$ & $\begin{array}{l}\text { Meireles \& da Silva } 1988 . \\
\text { Tassinari \& Mellito } 1994 . \\
\text { Mougeot ef al. 1996. Freitas- } \\
\text { Silva 1998. }\end{array}$ \\
\hline $\mathrm{Au}, \mathrm{Ag}$ & $\begin{array}{l}\text { Babaçu e Mamāo-Serra das } \\
\text { Andon-nhas (PA) }\end{array}$ & $\begin{array}{l}\text { Sedimentar química de } \\
\text { derivação vulcânica (BIF, } \\
\text { Chert), estratiforme. } \\
\text { Remobilização metamórfica. }\end{array}$ & $\begin{array}{c}2877-2970(\mathrm{P}) \\
(\mathrm{U}-\mathrm{Pb})\end{array}$ & $\begin{array}{l}\text { Silva \& Cordeiro } 1988 . \\
\text { Tassinari \& Mellito } 1994 . \\
\text { Macambira et al. 1996., }\end{array}$ \\
\hline $\mathrm{Au}, \mathrm{Ag}$ & $\begin{array}{l}\text { Lagoa Seca-Serra das } \\
\text { Andorinhas (PA) }\end{array}$ & $\begin{array}{l}\text { Au em metassedimentos } \\
\text { clásticos encaixados por rochas } \\
\text { máfica-ultramáficas. } \\
\text { Remobilização hidrotermal. }\end{array}$ & $>2870(\mathrm{I})$ & $\begin{array}{l}\text { Silva \& Cordeiro } 1988 . \\
\text { Macambira et al } 1996 .\end{array}$ \\
\hline $\mathrm{Alu}$ & Novo Planeta (MT) & Placer fluvial & $<1(\mathrm{P})$ & Veiga 1988 (a) \\
\hline $\mathrm{Au}, \mathrm{Cu}$ & Igarapé Bahia (PA) & $\begin{array}{l}\text { Vulcanogênico próximo, tipo } \\
\text { Millenbach, com "stringer ore". } \\
\text { Olimpic Dan? }\end{array}$ & $2700(p)$ & $\begin{array}{l}\text { Mougeot et al. 1996. Ferreira } \\
\text { Filho \& Danni 1985. Tallarico } \\
\text { et al. 1998a. Tallarico et al. } \\
\text { 1998b. Oliveira et al. } 1998 \text {. } \\
\text { Tavaza et al 1998. Ronchi \& } \\
\text { Lindenmayer 1998. }\end{array}$ \\
\hline Au & $\begin{array}{l}\text { Conjunto de depósítos do } \\
\text { Tapajos (PA-AM) }\end{array}$ & $\begin{array}{l}\text { Placer fluvial. Minério primário } \\
\text { em veios de quartzo em zonas de } \\
\text { cisalhamento (?). }\end{array}$ & $\begin{array}{l}\text { Placers <1 }(\mathrm{P}) \\
\text { Primário: } \\
1830-1859(\mathrm{p})\end{array}$ & Santos ef al 1997 \\
\hline $\begin{array}{l}\mathrm{Au}(\mathrm{Ag}, \\
\mathrm{Ba})\end{array}$ & Zacarias/Posse (GO) & Vulcanogênico próximo (?) & $860 \mathrm{Ma}(\mathrm{p})$ & $\begin{array}{l}\text { Arantes et al. 1991. Palermo } \\
\text { 1996. Kuyumjian } 1998\end{array}$ \\
\hline Au & Serrinha (MT) & $\begin{array}{l}\text { Apical disseminado, tipo } \\
\text { Porphyry. }\end{array}$ & $1872 \pm 12(\mathrm{P})$ & Moura \& Botelho 1998 \\
\hline $\begin{array}{l}\text { Barita, } \\
\text { gipsita }\end{array}$ & Camamu (BA) & $\begin{array}{l}\text { Stratabound, barita cimentando } \\
\text { arenitos. }\end{array}$ & $110-120(P)$ & $\begin{array}{l}\text { Bandeira et al. } 1986 \\
\text { Schobbenhaus \& Campos } 1984\end{array}$ \\
\hline Barita & Ibitiara (BA) & $\begin{array}{l}\text { Filöes hidrotermais } \\
\text { vulcanogênicos (?) }\end{array}$ & $1000-1100(\mathrm{P})$ & Schobbenhaus \& Campos 1984 \\
\hline Caulim & Rio Jari, Morro do Felipe (PA) & Sedimentar fluvio-lacustrino & $3-5(\mathrm{P})$ & Coura et al. 1986 \\
\hline Caulim & Rio Capim (PA) & Sedimentar fluvio-lacustrino(?) & & \\
\hline Caulim & Tijucas (PR) & Sedimentar fluvio-lacustrino & $<2(\mathrm{P})$ & \\
\hline Caulim & $\begin{array}{l}\text { Floresta, Cambui, Aruană, } \\
\text { Turvo.(SC) }\end{array}$ & $\begin{array}{l}\text { Hidrotermal vulcanogenico e } \\
\text { supergenico }\end{array}$ & $\begin{array}{l}\text { Hdrotermalismo }-500-570(\mathrm{P}) \\
\text { Supergênese- }-500(\mathrm{D})\end{array}$ & $\begin{array}{l}\text { Biondi \& Furtado 1999. Biondi } \\
1999\end{array}$ \\
\hline $\mathrm{Cr}$ & Limoeiro, Pedrinhas (BA) & $\begin{array}{l}\text { Estratiforme - Tipo Bushveld - } \\
\text { Great Dyke }\end{array}$ & $>2030(\mathrm{I})$ & $\begin{array}{l}\text { Duarte \& Fontes 1986. Giuliani } \\
\text { et al. 1994. } \\
\text { Glória da Silva \& Misi } 1998\end{array}$ \\
\hline$\overline{\mathrm{Cr}}$ & Medrado, Ipueira (BA) & $\begin{array}{l}\text { Estratiforme - Tipo Bushveld - } \\
\text { Great Dyke }\end{array}$ & $>2030(\mathrm{I})$ & $\begin{array}{l}\text { Mello ef al. 1986. Giuliani el al. } \\
\text { 1994. Glória da Silva \& Misi } \\
1998\end{array}$ \\
\hline $\mathrm{Cr}$ & Pedras Pretas (BA) & $\begin{array}{l}\text { Estratiforme - Tipo Bushveld - } \\
\text { Great Dyke }\end{array}$ & $>2030(\bar{I})$ & $\begin{array}{l}\text { Carvalho Filho et al. } 1986 . \\
\text { Giuliani et al. 1994. Gloria da } \\
\text { Silva \& Misi } 1998\end{array}$ \\
\hline $\begin{array}{l}\mathrm{Cu}(\mathrm{Au}, \\
\mathrm{Ag})\end{array}$ & Uruguai, São Luiz (RS) & $\begin{array}{l}\text { Minério em veios e disseminado. } \\
\text { Tipo porphyry? }\end{array}$ & $\begin{array}{c}\text { Minério - 560-590(P) } \\
\text { (592 Ma Pb-Pb) } \\
\text { Filitizaçăo-538 (K-Ar) (p) } \\
\text { Cloritizaçãa-515 (K-Ar) (p) } \\
\text { Argilização-474 (K-Ar) (p) }\end{array}$ & $\begin{array}{l}\text { Teixeira \& Gonzalez } 1988 . \\
\text { Remus et al. 1997. Biondi } 1997 \\
\text { a. }\end{array}$ \\
\hline
\end{tabular}


Tabela l-Continuação

\begin{tabular}{|c|c|c|c|c|}
\hline MINÉRЮ & $\begin{array}{c}\text { NOME DO } \\
\text { DEPOSITO } \\
\text { (Estado) }\end{array}$ & $\begin{array}{l}\text { MODELO GENÉTICO } \\
\text { PROVAVEL }\end{array}$ & $\begin{array}{l}\text { IDADE DA MINERALZAÇÃO } \\
(\mathrm{Min}-\mathrm{Max}) \\
(\mathrm{Ma})\end{array}$ & REFERENCIA \\
\hline $\mathrm{Cu}$ & Caraiba, Surubim (BA) & $\begin{array}{l}\text { Contaminação externa por S. } \\
\text { Tipo Duluth/Noril'sk (?) }\end{array}$ & $\begin{array}{c}\text { Intrusão }=2250(\mathrm{p}) \\
\text { Metamorfismo }=1800-2020(\mathrm{~Pb}-\mathrm{Pb}) \\
(\mathrm{P})\end{array}$ & $\begin{array}{l}\text { Lima e Silva et al. 1988. D'El } \\
\text { Rey Silva } 1985 \text {. D'El Rey Silva } \\
\text { \& Oliveira } 1998\end{array}$ \\
\hline $\mathrm{Cu}$ & Suçuarana (BA) & $\begin{array}{l}\text { Contaminação externa por S. } \\
\text { Tipo Duluth/Noril'sk (?) }\end{array}$ & $\begin{array}{c}\text { Intrusāo }=2250(\mathrm{p}) \\
\text { Metamorfismo }=1800-2020(\mathrm{~Pb}-\mathrm{Pb}) \\
(\mathrm{P})\end{array}$ & $\begin{array}{l}\text { Lima e Silva et al. 1988. D'El } \\
\text { Rey Silva 1985. D'El Rey Silva } \\
\text { \& Oliveira } 1998\end{array}$ \\
\hline $\mathbf{C u}$ & Vermelho (BA) & $\begin{array}{l}\text { Contaminaçāo externa por S. } \\
\text { Tipo Duluth/Noril'sk (?) }\end{array}$ & $\begin{array}{c}\text { Intrusão }=2250(\mathrm{p}) \\
\text { Metamorfismo }=1800-2020(\mathrm{~Pb} \cdot \mathrm{Pb}) \\
(\mathrm{P})\end{array}$ & $\begin{array}{l}\text { Lima e Silva et al. 1988. D'El } \\
\text { Rey Silva 1985. D'El Rey Silva } \\
\text { \& Oliveira 1998 } \\
\end{array}$ \\
\hline $\mathrm{Cu}$ & Surubim (BA) & $\begin{array}{l}\text { Contaminação externa por S. } \\
\text { Tipo Duluth/Noril'sk (?) }\end{array}$ & $\begin{aligned} & \text { Intrusåo }=2250(\mathrm{p}) \\
& \text { Metamorfismo }=1800-2020(\mathrm{~Pb}-\mathrm{Pb}) \\
&(\mathrm{P})\end{aligned}$ & $\begin{array}{l}\text { Lima e Silva et al. 1988. D'El } \\
\text { Rey Silva 1985. D'El Rey Silva } \\
\text { \& Oliveira } 1998\end{array}$ \\
\hline $\mathrm{Cu}$ & Pirulito (BA) & $\begin{array}{l}\text { Contaminaçăo externa por S. } \\
\text { Tipo Duluth/Noril'sk (?) }\end{array}$ & $\begin{array}{c}\text { Intrusão }=2250(\mathrm{p}) \\
\text { Metamorfismo }=1800-2020(\mathrm{~Pb}-\mathrm{Pb}) \\
(\mathrm{P})\end{array}$ & $\begin{array}{l}\text { Lima e Silva et al. 1988. D'El } \\
\text { Rey Silva 1985. D'El Rey Silva } \\
\text { \& Oliveira } 1998\end{array}$ \\
\hline $\mathrm{Cu}$ & Bota Sela (BA) & $\begin{array}{l}\text { Contaminação externa por S. } \\
\text { Tipo Duluth/Noril'sk (?) }\end{array}$ & $\begin{array}{c}\text { Intrusão }=2250(\mathrm{p}) \\
\text { Metamorfismo }=1800-2020(\mathrm{~Pb}-\mathrm{Pb}) \\
(\mathrm{P})\end{array}$ & \begin{tabular}{|l} 
Lima e Silva et al. 1988. D'El \\
Rey Silva 1985. D'El Rey Silva \\
\& Oliveira 1998 \\
\end{tabular} \\
\hline $\begin{array}{l}\mathrm{Cu}(\mathrm{Au}, \mathrm{Ni}, \\
\mathrm{V})\end{array}$ & Serrote da Laje (AL) & Tipo Duluth/Noril'sk (?) & $1800-2020(p)$ & Horbach \& Marinon 1988 \\
\hline $\mathrm{Cu}(\mathrm{Ag})$ & Pedra Verde (CE) & $\begin{array}{l}\text { Concentraçāo supergênica } \\
\text { Mesoproterozóica sobre filitos } \\
\text { com sulfetos disseminados (?). }\end{array}$ & 1150 (I) & Brizzi \& Roberto 1988 \\
\hline $\begin{array}{l}\mathrm{Cu}(\mathrm{Fe}, \mathrm{Au} \\
\mathrm{Mo}, \mathrm{Ag})\end{array}$ & Salobo (PA) & $\begin{array}{l}\text { Vulcanogênico exalativo } \\
\text { distante (SEDEX) } \\
\text { Remobilização tardia e } \\
\text { hidrotermalismo. (Tipo Au-Cu- } \\
\text { Magnetita, australiano?) } \\
\end{array}$ & $\begin{array}{c}\text { SEDEX -2732-2742(P) } \\
2762-2776(\mathrm{l}) \\
\text { Metamorf.-2000-2200 (p) } \\
\text { Hidrotermalismo-1880 (P) }\end{array}$ & $\begin{array}{l}\text { Amaral, E.V. et al. 1988. } \\
\text { Mougeot et al. 1996. Réquia \& } \\
\text { Xavier 1995. Figueiredo et al. } \\
\text { 1994. Lindenmayer 1998. } \\
\text { Mellito \& Tassinari 1998. }\end{array}$ \\
\hline $\mathrm{Cu}, \mathrm{Zn}$ & Pojuca (PA) & \begin{tabular}{|l|} 
Vulcanogênico exalativo \\
distante (SEDEX). \\
Remobilização tardia e \\
hidrotermalismo. (Tipo Au-Cu- \\
Magnetita, australiano?) \\
\end{tabular} & $\begin{array}{c}\text { SEDEX -2732-2742 }(\mathrm{P}) \\
\text { Metamorf.-2000-2200 (p) } \\
\text { Hidrotermalismo-1880 (P) }\end{array}$ & $\begin{array}{l}\text { Schobbenhaus \& Coelho } 1988 . \\
\text { Mougeot } \text { et al. } 1996 \text {. Figueiredo } \\
\text { et al. 1994. Medeiros Neto \& } \\
\text { Villas 1985. Medeiros Neto } \\
\text { 198a, 1986b. Lindenmayer } 1998\end{array}$ \\
\hline $\mathrm{Cu}(\mathrm{Au})$ & Bom Jardim (GO) & $\begin{array}{l}\text { Vulcanogênico próximo. } \\
\text { Redistribuiçåo metamórfica. }\end{array}$ & $\begin{array}{l}\text { Fase vulcanogênica- } 800(\mathrm{p}) \\
\text { Metamorfismo }=532(\mathrm{P})\end{array}$ & Seer 1985. Kuyumjian 1998 \\
\hline $\mathrm{Cu}, \mathrm{Fe}$ & Sossêgo (PA) & Apical disseminado. & $2700(\mathrm{D})$ & Informação verbal. \\
\hline $\mathrm{Cu}$ & Santa Blandina (SP) & & & Informação verbal. \\
\hline Diaman-te & Jequitinhonha (MG) & Placer fluvial & $<1(\mathrm{P})$ & $\begin{array}{l}\text { Chaves \& Uhlein 1981. Dupont } \\
1981 .\end{array}$ \\
\hline Diaman-te & Fazenda Camargo (MT) & Placer fluvial & $<1(\mathrm{P})$ & Carvalho et al. 1981 \\
\hline Diaman-te & Poxoréu, Juína (MT) & Placer fluvial & $<1(\mathrm{P})$ & Souza 1981. Haraly 1981 \\
\hline Diaman-te & Paranatinga (MT) & Kimberlitos & $121(\mathrm{P})$ & $\begin{array}{l}\text { Gonzaga \& Tompkins } 1981 . \\
\text { Tompkins \& Gonzaga 1989, }\end{array}$ \\
\hline Diaman-te & $\begin{array}{l}\text { Conjunto de depositos da } \\
\text { Chapada Diamantina (BA) }\end{array}$ & Paleoplacer e placer aluvial & $<1(\mathrm{P})$ & Costa 1981 \\
\hline Diaman-te & $\begin{array}{l}\text { Conjunto de depósitos de } \\
\text { Roraima (RO) }\end{array}$ & Alluvial placers & $<1(\mathrm{P})$ & Rodrigues 1981 \\
\hline Diaman-te & Cotomandel (MG) & Kimberlitos, placers fluviais & $53-87(\mathrm{P})$ & $\begin{array}{l}\text { Tompkins \& Gonzaga } 1989 . \\
\text { Schobbenhaus \& Campos } 1984\end{array}$ \\
\hline Esme-ralda & Itabira (MG) & $\begin{array}{l}\text { Esmeralda no contato de } \\
\text { pegmatitos encaixados em } \\
\text { vulcânicas básicas. }\end{array}$ & $500-700(\mathrm{I})$ & $\begin{array}{l}\text { Souza 1991. Cassedane \& Sauer } \\
\text { 1988. Giuliani } \quad \text { et al. } 1990 . \\
\text { Schwarz } 1986 \\
\end{array}$ \\
\hline Esme-ralda & Santa Terezinha (GO) & $\begin{array}{l}\text { Hidrotermalismo em zonas de } \\
\text { cisalhamento de baixo ângulo. }\end{array}$ & $476-478(P)$ & $\begin{array}{l}\text { Costa \& Sá 1991. Biondi \& } \\
\text { Poidevin } 1994\end{array}$ \\
\hline Esme-ralda & Minaçu (GO) & $\begin{array}{l}\text { Similar a Santa Terezinha. } \\
\text { Hidrotermalismo em zonas de } \\
\text { cisalhamento de baixo ângulo. }\end{array}$ & $476-478(P))$ & Biondi \& Poidevin 1994 \\
\hline Esme-ralda & Carnaiba, Socotó (BA) & $\begin{array}{l}\text { Esmeralda no contato de } \\
\text { pegmatitos encaixados em } \\
\text { vulcânicas básicas. }\end{array}$ & $\begin{array}{l}1976(\mathrm{Ar}-\mathrm{Ar})(\mathrm{P}) \\
1973(\mathrm{~K}-\mathrm{Ar})(\mathrm{P})\end{array}$ & $\begin{array}{l}\text { Couto et al. 1991. Glória da } \\
\text { Silva \& Misi 1998. Giuliani et } \\
\text { al. 1990. Giuliani et al. } 1994\end{array}$ \\
\hline $\mathbf{F}$ & Morro da Fumaça, Fortuna (SC) & $\begin{array}{l}\text { Filões formados por lixiviação } \\
\text { hidatogênica de granitoides. }\end{array}$ & $115-130(\mathrm{P})$ & Bastos Neto et al. 1991 \\
\hline
\end{tabular}


Tabela l-Continuação

Tabela l-Continuação

\begin{tabular}{|c|c|c|c|c|}
\hline MINERIO & $\begin{array}{l}\text { NOME DO } \\
\text { DEPÓSFTO } \\
\text { (Estado) }\end{array}$ & $\begin{array}{l}\text { MODELO GENÉTICO } \\
\text { PROVAVEL }\end{array}$ & $\begin{array}{c}\text { DADE DA MINERALZZ AÇAO } \\
(\mathrm{Min}-\mathrm{Max}) \\
(\mathrm{Ma})\end{array}$ & REFERENNCLA \\
\hline $\mathbf{F}$ & Tanguá-Rio Bonito (RJ) & $\begin{array}{l}\text { Filbes relacionados a intrusðes } \\
\text { alcalinas. }\end{array}$ & $100-120(\mathrm{P})$ & Coelho et al. 1986 \\
\hline F, REE & Mato Preto (PR) & $\begin{array}{l}\text { Fluorita maciça e disseminada } \\
\text { em carbonatitos. }\end{array}$ & $60-90(P)$ & Ruberti et al. 1997 \\
\hline $\mathrm{Fe}$ & Alegria (MG) & BIF gigante, tipo Superior & $2420-2600(\mathrm{~Pb}-\mathrm{Pb})(\mathrm{P})$ & $\begin{array}{l}\text { Barcelos et al. 1996. Babinski et } \\
\text { al. } 1995\end{array}$ \\
\hline $\mathrm{Fe}$ & Capanema (MG) & BIF gigante, tipo Superior & $2420-2600(\mathrm{~Pb}-\mathrm{Pb})(\mathrm{P})$ & $\begin{array}{l}\text { Guimaräes et al. } 1986 . \\
\text { Machado et al. } 1996 . \text { Babinskief } \\
\text { al. } 1995\end{array}$ \\
\hline $\mathrm{Fe}$ & Timbopeba (MG) & BJF gigante, tipo Superior & $2420-2600(\mathrm{~Pb}-\mathrm{Pb})(\mathrm{P})$ & $\begin{array}{l}\text { Vasconcelos et al. } 1986 . \\
\text { Machado et al. 1996. Babinski et } \\
\text { al. 1995 }\end{array}$ \\
\hline $\mathrm{Fe}$ & $\begin{array}{l}\text { Aguas Claras, Mutuca, Picos } \\
\text { (MG) }\end{array}$ & BIF gigante, tipo Superior & $2420-2600(\mathrm{~Pb}-\mathrm{Pb})(\mathrm{P})$ & $\begin{array}{l}\text { Gomes 1986. Machado et al. } \\
\text { 1996. Babinski et al. } 1995\end{array}$ \\
\hline $\mathrm{Fe}$ & $\begin{array}{l}\text { Cauê, Conceição, Dois } \\
\text { Córregos, Periquito, Onça, } \\
\text { Chacrinha e Esmeril (MG) }\end{array}$ & BIF gigante, tipo Superior & $2420-2600(\mathrm{~Pb}-\mathrm{Pb})(\mathrm{P})$ & $\begin{array}{l}\text { Melo et al. 1986. Machado et } \\
\text { al. 1996. Babinski et al. } 1995\end{array}$ \\
\hline $\mathrm{Fe}$ & $\begin{array}{l}\text { Poneirinha, Rio Pardo de Minas, } \\
\text { Riacho dos Machados e Grão- } \\
\text { Mogol (MG0 }\end{array}$ & $\begin{array}{l}\text { Conglomerados (diamictitos?) } \\
\text { cimentados por hematita. } \\
\text { Interacamadamento com rochas } \\
\text { sedimentares bandadas ricas em } \\
\text { ferto (BIF?) } \\
\end{array}$ & & Vilela 1986 \\
\hline $\mathrm{Fe}$ & $\begin{array}{l}\mathrm{N} 1, \mathrm{~N} 2, \mathrm{~N} 3, \mathrm{~N} 4, \mathrm{~N} 5, \mathrm{~N} 6, \mathrm{~N} 9 \mathrm{e} \\
\text { Sil } 1 \text { (PA) }\end{array}$ & $\begin{array}{l}\text { BIF gigante, tipo Superior } \\
\text { Concentração } \\
\text { supergênica/residual. }\end{array}$ & $2757(\mathrm{~Pb}-\mathrm{Pb}$ em zircão) (P) & $\begin{array}{l}\text { Coelho 1986. Macambira et al. } \\
1996\end{array}$ \\
\hline Gipsita & Maraú (BA) & Evaporito & $100-110(\mathrm{P})$ & \\
\hline Gipsita & $\begin{array}{l}\text { Conjunto de depositos da Bacia } \\
\text { do Araripe (PI, PE, CE) }\end{array}$ & Evaporito & $70-90(\mathrm{P})$ & \\
\hline Gipsita $\mathrm{Na}$ & Aveiro (PA) & Evaporito & $100-110(\mathrm{P})$ & \\
\hline Gipsita & Codó (MA) & Evaporito & $100-110(\mathrm{P})$ & \\
\hline $\mathrm{K}, \mathrm{Na}(\mathrm{Mg})$ & Taquari, Vassouras (SE) & Evaporito & $100-110(\mathrm{P})$ & \\
\hline $\mathrm{K}, \mathrm{Na}$ & Nova Olinda (AM) & & & \\
\hline $\begin{array}{l}\text { Magnesita, } \\
\text { talco. }\end{array}$ & Brumado (BA) & $\begin{array}{l}\text { Magnesita=sedimentar químico? } \\
\text { Talco = metamorfismo sobre } \\
\text { rochas ultramáficas e dolomitos. }\end{array}$ & $\begin{array}{l}\text { Magnesita }=2700(\mathrm{D}) \\
\text { Talco }=500-550(\mathrm{p})\end{array}$ & $\begin{array}{l}\text { Schobbenhaus \& Campos } 1984 . \\
\text { Delgado \& Pedreira } 1994\end{array}$ \\
\hline Magnesita & Sento-Sé (BA) & $\begin{array}{l}\text { Metamorfismo sobre rochas } \\
\text { ultamaficas (komatiiticas?) }\end{array}$ & $\begin{array}{c}2000(\mathrm{I}) \\
500-550(\mathrm{p})\end{array}$ & Delgado \& Pedreira 1994 \\
\hline Magnesita & Orós (CE) & $\begin{array}{l}\text { Metamorfismo sobre rochas } \\
\text { ultamáficas (komatiticas?) }\end{array}$ & $\begin{array}{c}2000(\mathrm{I}) \\
500-550(\mathrm{p})\end{array}$ & Delgado \& Pedreira . 1994 \\
\hline $\mathrm{Mn}, \mathrm{Fe}$ & Urucum (MS) & $\begin{array}{l}\text { Minério estratiforme sedimentar } \\
\text { depositado em amb iente fluvio- } \\
\text { lacustrino a marinho raso. }\end{array}$ & $850-950(\mathrm{P})$ & Haraly \& Walde 1986 \\
\hline $\mathbf{M n}$ & $\begin{array}{l}\text { Pedra Preta, Barnabé, Lagoa } \\
\text { D'Anta (BA) }\end{array}$ & $\begin{array}{l}\text { Enriquecimento residual sobre } \\
\text { rochas carbonatadas ricas em } \\
\text { Mn e sobre quartzitos } \\
\text { manganesiferos (gonditos). }\end{array}$ & $\begin{array}{c}\text { Sedimentação-? } \\
\text { Enriquecimento residual }=10-50(P)\end{array}$ & $\begin{array}{l}\text { Biondi 1972. Basílio \& Brondi } \\
1986\end{array}$ \\
\hline $\mathrm{Mn}$ & Ventador, Tauá, (BA0 & $\begin{array}{l}\text { Enriquecimento residual sobre } \\
\text { gonditos }\end{array}$ & $\begin{array}{c}\text { Sedimentaçăo }-? \\
\text { Enriquecimento residual }=10-50(\mathrm{P})\end{array}$ & $\begin{array}{l}\text { Biondi 1972. Basílio \& Brondi } \\
1986 \text {. }\end{array}$ \\
\hline $\mathbf{M n}$ & Azul (PA) & $\begin{array}{l}\text { Enriquecimento residual e } \\
\text { supergênico sobre rochas } \\
\text { carbonáticas rodocrosíticas. }\end{array}$ & $\begin{array}{c}\text { Sedimentaçåo-2681(P) } \\
(2708-27787) \\
\text { Enriquecimento residu- } \\
\text { al/supergênico-25-55 (P) }\end{array}$ & $\begin{array}{l}\text { Coelho \& Rodrigues } 1986 . \\
\text { Mougeot et al. } 1996 .\end{array}$ \\
\hline $\mathrm{Mn}$ & Serra do Buritirama (PA) & $\begin{array}{l}\text { Enriquecimento residual e } \\
\text { supergênico sobre rochas } \\
\text { carbonáticas rodocrosíticas. }\end{array}$ & $\begin{array}{c}\text { Sedimentaçăo-2681(P) } \\
\text { (2708-2778?) } \\
\text { Enriquecimento residu- } \\
\text { al/supergenico-25-55 (P) }\end{array}$ & $\begin{array}{l}\text { Andrade et al. } 1986 \text {. Mougeot et } \\
\text { al. } 1996 .\end{array}$ \\
\hline Mn & Serra do Navio (AP) & $\begin{array}{l}\text { Enriquecimento residual e } \\
\text { supergênico sobre tochas } \\
\text { carbonáticas rodocrosíticas. }\end{array}$ & $\begin{array}{l}\text { Sedimentaçao-1800-2200 (I) } \\
\text { Entiquecimento residu- } \\
\text { al/supergenico -25-55 (P) }\end{array}$ & Rodrigues et al. 1986 \\
\hline Mn & Lafaiete (MG) & & & \\
\hline $\mathrm{Fe}, \mathrm{Mn}$ & Miguel Congo (MG) & $\begin{array}{l}\text { Formaçōes ferríferas gigantes, } \\
\text { tipo Superior. }\end{array}$ & $2420-2600(\mathrm{~Pb}-\mathrm{Pb})(\mathrm{P})$ & $\begin{array}{l}\text { Barcelos \& Buchi } 1986 . \\
\text { Babinski et al. 1995. Machado et } \\
\text { al. } 1996\end{array}$ \\
\hline
\end{tabular}


Tabela l-Continuação

\begin{tabular}{|c|c|c|c|c|}
\hline MINÉRIO & $\begin{array}{c}\text { NOME DO } \\
\text { DEPÓSTO } \\
\text { (Estado) }\end{array}$ & $\begin{array}{l}\text { MODELO GENÉTICO } \\
\text { PROVAVEL }\end{array}$ & $\begin{array}{c}\text { IDADE DA MINERAUZAÇÃO } \\
(\text { Min - Max }) \\
(\mathrm{Ma}) \\
\end{array}$ & REFERENCLA \\
\hline $\mathrm{Mo}, \mathrm{U}$ & Agostinho (MG) & $\begin{array}{l}\text { Mo e U na matriz de brechas de } \\
\text { fluidização em diques de rochas } \\
\text { alcalinas. }\end{array}$ & $60-87(\mathrm{P})$ & \\
\hline $\mathrm{Na}, \mathrm{K}$ & Nova Olinda (AM) & Evaporitos & $225-270(\mathrm{P})$ & Schobbenhaus \& Campos 1984 \\
\hline $\begin{array}{l}\mathrm{Nb}, \mathrm{P}, \mathrm{Ba} \\
\text { (Ti) }\end{array}$ & Araxá (MG) & $\begin{array}{l}\text { Enriquecimento residual sobre } \\
\text { carbonatitos com pirocloro e } \\
\text { apatita. }\end{array}$ & $87,2-95,3(\mathrm{P})$ & $\begin{array}{l}\text { da Silva 1986. Hasui \& Cordani } \\
1962\end{array}$ \\
\hline $\begin{array}{l}\text { Nb,P, Ti, } \\
\text { vermi- } \\
\text { culita }\end{array}$ & Catalấo I $(\mathrm{GO})$ & $\begin{array}{l}\text { Enriquecimento residual sobre } \\
\text { carbonatitos com pirocloro, } \\
\text { apatita e anatasio. }\end{array}$ & $82,9(\mathrm{P})$ & $\begin{array}{l}\text { Gierth \& Baecker 1986. Hasui } \\
\text { \& Cordani } 1962\end{array}$ \\
\hline $\begin{array}{l}\text { Nb, TR, Th, } \\
\text { Ti }\end{array}$ & Morro dos Sejs Lagos (AM) & $\begin{array}{l}\text { Mínério laterítico. } \\
\text { Enriquecimento residual sobre } \\
\text { carbonatitos com Nb-rutilo, } \\
\text { monazita e gorceixita. }\end{array}$ & $\begin{array}{l}\text { Laterita }-25-55(\mathrm{P}) \\
\text { Carbonatito- (?) }\end{array}$ & $\begin{array}{l}\text { Justo \& Souza 1986. Issler \& } \\
\text { Silva 1980. Bonow \& Issler } \\
1980\end{array}$ \\
\hline $\begin{array}{l}\mathrm{Ni}, \mathrm{Cu}, \mathrm{Co} \\
\mathrm{EPG}\end{array}$ & Mina O'Toole (MG) & $\begin{array}{l}\text { Depósito tipo Scotia. Sulfetos } \\
\text { maciços e disseminados na base } \\
\text { de sequência komatiitica }\end{array}$ & $>2500(\mathrm{I})$ & \begin{tabular}{|lll} 
Cruz & et al. 1986. Marchetto \\
1986 & &
\end{tabular} \\
\hline $\mathrm{Ni}, \mathrm{Cu}, \mathrm{Co}$ & Americano do Brasil (GO) & $\begin{array}{l}\text { Depósito tipo Duluth } \\
\text { (Waterhem). Sulfetos de Ni e Cu } \\
\text { gerados por contaminação } \\
\text { externa de } S \text { na base de um } \\
\text { maciço peridotítico. } \\
\end{array}$ & 960 (I) -K-Ar em homblenda & Nilson ef al. 1986. \\
\hline $\mathrm{Ni}$ & Morro do Niquel (MG) & Minério residual, laterítico. & $55-0(P)$ & $\begin{array}{l}\text { Schobbenhaus \& Coelho, C.E.S. } \\
\text { (Eds.) } 1986\end{array}$ \\
\hline $\mathrm{Ni}$ & Morro do Corisco (MG) & Minério residual, laterítico. & $55-0(\mathrm{P})$ & $\begin{array}{l}\text { Schobbenhaus \& Coelho, C.E.S. } \\
\text { (Eds.) } 1986\end{array}$ \\
\hline $\mathrm{Ni}, \mathrm{Cu}$ & Pocrane (MG) & Minério residual, laterítico. & $55-0(\mathrm{P})$ & $\begin{array}{l}\text { Schobbenhaus \& Coelho. C.E.S. } \\
\text { (Eds.) } 1986\end{array}$ \\
\hline $\mathrm{Ni}$ & Morto do Engenho (GO) & Minério residual, laterítico. & $55-0(\mathrm{P})$ & Berbert 1986 \\
\hline $\mathrm{Ni}$ & Salobinha (GO) & Minério residual, laterítico. & $55-0(\mathrm{P})$ & $\begin{array}{l}\text { Schobbenhaus \& Coelho, C.E.S, } \\
\text { (Eds.) } 1986\end{array}$ \\
\hline $\mathrm{Ni}$ & Santa Fé (GO) & Minério residual, laterítico. & $55-0(\mathrm{P})$ & $\begin{array}{l}\text { Schobbenhaus \& Coelho, C.E.S } \\
\text { (Eds.) } 1986\end{array}$ \\
\hline $\mathrm{Ni}$ & Serra de Água Branca (GO) & Minério residual, laterítico. & 55-0 (P) & $\begin{array}{l}\text { Schobbenhaus \& Coetho, C.E.S. } \\
\text { (Eds.) } 1986\end{array}$ \\
\hline $\mathrm{Ni}$ & Fazenda Furnas (GO) & Minério residual, laterítico. & $55-0(\mathrm{P})$ & $\begin{array}{l}\text { Schobbenhaus \& Coelho, C.E.S } \\
\text { (Eds.) } 1986\end{array}$ \\
\hline $\mathrm{Ni}$ & Rio dos Bois (GO) & Minério residual, laterítico. & $55-0(\mathrm{P})$ & $\begin{array}{l}\text { Schobbenhaus \& Coelho, C.E.S } \\
\text { (Eds.) } 1986\end{array}$ \\
\hline $\mathrm{Ni}, \mathrm{Co}_{\mathrm{O}}$ & Barto Alto $(\mathrm{GO})$ & Minério residual, laterítico. & $55-0(\mathrm{P})$ & Baeta Jr. 1986 \\
\hline $\mathrm{Ni}, \mathrm{Co}$ & Niquelầndia (GO) & Minério residual, laterítico. & 55-0 (P) & Pedroso \& Schmaltz 1986 \\
\hline $\begin{array}{l}\mathrm{Ni} \text {, Vermi- } \\
\text { culita }\end{array}$ & Serra de Água Branca (GO) & Minério residual, laterítico. & $55-0(\mathrm{P})$ & \\
\hline $\mathrm{Ni}$ & Vermelho (PA) & Minerio residual, Jaterítico. & $55-0(P)$ & Alves et al. 1986 \\
\hline $\mathrm{Ni}$ & Quatipuru (PA) & Minério zesidual, Jaterf́tico. & $55-0(\mathrm{P})$ & Schobbenhaus 1986 \\
\hline $\mathrm{Ni}$ & Puma-Onça, (PA) & Minério residual, laterítico. & $55-0(\mathrm{P})$ & Heim \& Castro Filho 1986 \\
\hline $\mathrm{Ni}$ & Jacaré, Jacarezinho (PA) & Minério residual, laterítico. & $55-0(\mathrm{P})$ & Castro Filho \& Mattos 1986 \\
\hline $\mathrm{Ni}$ & Brejo Seco (PD) & Minério residual, laterítico. & 11-0(P) & Santos 1986 \\
\hline $\mathrm{Ni}$ & Ribeirão do Joelho (SP) & Minério residual, laterítico. & $55-0(\mathrm{P})$ & Schobbenhaus 1986 \\
\hline Opala & Pedro II (PI) & & & Roberto \& Souza 1991. \\
\hline $\mathbf{P}$ & Catalāo I (GO) & $\begin{array}{l}\text { Enriquecimento residual sobre } \\
\text { carbonatitos. }\end{array}$ & & \\
\hline $\mathbf{P}$ & Anitápolis (SC) & $\begin{array}{l}\text { Enriquecimento residual sobre } \\
\text { carbonatitos. }\end{array}$ & $\begin{array}{c}\text { Rochas alcalinas-129 (P) } \\
\text { Enriquecimento residual-55-0 (P) }\end{array}$ & Schobbenhaus \& Campos 1984 \\
\hline $\mathbf{P}$ & Angico dos Dias (BA) & $\begin{array}{l}\text { Enriquecimento residual sobre } \\
\text { carbonatitos. } \\
\end{array}$ & $\begin{array}{c}\text { Carbonatito-2011(P) } \\
\text { Minério residual-55(?)-0 (p) }\end{array}$ & Silva et al 1987 \\
\hline $\mathrm{P}$ & Patos de Minas (MG) & Fosforita metamorfisada? & $600-650(\mathrm{I})$ & Schobbenhaus \& Campos 1984 \\
\hline $\begin{array}{l}\text { vermiculita } \\
\text { (Fe, Ti) }\end{array}$ & Ipanema (SP) & $\begin{array}{l}\text { Enriquecimento residual sobre } \\
\text { rochas alcalinas. }\end{array}$ & $53-82(\mathrm{P})$ & $\begin{array}{l}\text { Leinz } 1940 . \text { Schobbenhaus } \& \\
\text { Campos } 1984\end{array}$ \\
\hline $\mathrm{P}, \mathrm{Nb}, \mathrm{Ti}$ & Tapira (MG) & $\begin{array}{l}\text { Enriquecimento residual sobre } \\
\text { rochas alcalinas. }\end{array}$ & $69,5(\mathrm{~K}-\mathrm{Ar})(\mathrm{P})$ & Hasui \& Cordani 1962 \\
\hline $\mathrm{P}(\mathrm{Pb}-\mathrm{Zn})$ & Irecề (MG) & Fosforitas sedimentares. & $600-650(\mathrm{I})$ & Bomfim 1986. Misi et al, 1998 \\
\hline
\end{tabular}


Tabela l-Continuação

\begin{tabular}{|c|c|c|c|c|}
\hline MINÉRIO & $\begin{array}{c}\text { NOME DO } \\
\text { DEPÓSITO } \\
\text { (Estado) }\end{array}$ & $\begin{array}{l}\text { MODELO GENETICO } \\
\text { PROVAVEL }\end{array}$ & $\begin{array}{l}\text { IDADE DA MINERALZAÇĀO } \\
\text { (Min - Max) } \\
(\mathrm{Ma}) \\
\end{array}$ & REFERENCIA \\
\hline $\mathbf{P}$ & $\begin{array}{l}\text { Alhandra, João Pessoa, Igaraçu } \\
\text { and Goiana (PB-PE) }\end{array}$ & Fosforitas sedimentares. & $65-80(\mathrm{P})$ & Delgado \& Pedreira 1994 \\
\hline $\begin{array}{l}\text { P, calcário, } \\
\text { (Fe) }\end{array}$ & Jacupiranga (SP) & Apatita em carbonatito. & $131(\mathrm{P})$ & Ruberti et al. 1991 \\
\hline $\mathrm{Pb}, \mathrm{Zn}(\mathrm{Ag})$ & Santa Maria (RS) & $\begin{array}{l}\text { Cimentação diagenética de } \\
\text { sedimentos vulcanoclásticos. }\end{array}$ & $\begin{array}{l}\text { Filös=560-590 } \\
(592 \mathrm{~Pb}-\mathrm{Pb} ?)(\mathrm{p})\end{array}$ & $\begin{array}{l}\text { Badi \& Gonzalez 1988. Remus } \\
\text { et al. } 1997 .\end{array}$ \\
\hline $\begin{array}{l}\mathrm{Pb}, \mathrm{Ag}(\mathrm{Cu}, \\
\mathrm{Zn})\end{array}$ & Perau (PR) & $\begin{array}{l}\text { Estratiforme, vulcanogênico } \\
\text { distante, exalativo. }\end{array}$ & $1639-1799(\mathrm{~Pb}-\mathrm{Pb})(\mathrm{p})$ & da Silva et al. 1988. Daitx 1997 \\
\hline $\mathrm{Pb}, \mathrm{Ag}(\mathrm{Zn})$ & Canoas (PR) & $\begin{array}{l}\text { Estratiforme, vulcanogênico } \\
\text { distante, exalativo. }\end{array}$ & $1626-1843(\mathrm{~Pb}-\mathrm{Pb})(\mathrm{p})$ & Daitx 1997 \\
\hline $\mathrm{Pb}, \mathrm{Ag}(\mathrm{Zn})$ & Araçazeiro (PR) & $\begin{array}{l}\text { Estratiforme, vulcanogênico } \\
\text { distante, exalativo. }\end{array}$ & $1615(\mathrm{~Pb}-\mathrm{Pb})(\mathrm{p})$ & Daitx 1997 \\
\hline $\mathrm{Pb}, \mathrm{Ag}(\mathrm{Zn})$ & João Neri (PR) & $\begin{array}{l}\text { Estratiforme, vulcanogênico } \\
\text { distante, exalativo. }\end{array}$ & $1496-1600(\mathrm{~Pb}-\mathrm{Pb})(\mathrm{p})$ & Daitx 1997 \\
\hline $\mathrm{Pb}, \mathrm{Ag}$ & Rocha (São Marcos) (PR) & Mississippi Valley, filoneano. & $1106-1250(\mathrm{~Pb}-\mathrm{Pb})(\mathrm{p})$ & $\begin{array}{l}\text { Acciari Jr et al. 1988. Daitx } \\
1997\end{array}$ \\
\hline $\mathrm{Pb}, \mathrm{Ag}$ & Panelas (PR) & Mississippi Valley, filoneano. & $1238-1255(\mathrm{~Pb}-\mathrm{Pb})(\mathrm{p})$ & Zaccarelli 1988. Daitx 1997 \\
\hline $\mathrm{Pb}, \mathrm{Ag}$ & Lageado (SP) & Mississippi Valley, filoneano. & $1102-1266(\mathrm{~Pb}-\mathrm{Pb})(\mathrm{p})$ & Daitx 1997 \\
\hline $\mathrm{Pb}, \mathrm{Ag}$ & Furnas (SP) & Mississippi Valley, filoneano. & $1093-1226(\mathrm{~Pb}-\mathrm{Pb})(\mathrm{p})$ & Daitx 1997 \\
\hline $\mathrm{Pb}, \mathrm{Ag}$ & Barrinha (São Braz) (PR) & Mississippi Valley, filoneano? & $1020-1084(\mathrm{~Pb}-\mathrm{Pb})(\mathrm{p})$ & Daitx 1997 \\
\hline $\mathrm{Pb}, \mathrm{Zn}, \mathrm{Ag}$ & Boquira (BA) & \begin{tabular}{|l|} 
Sedimentar químico, \\
estratiforme (vulcanogênico \\
distante?)
\end{tabular} & $2500-2700(\mathrm{~Pb}-\mathrm{Pb})(\mathrm{I})$ & $\begin{array}{l}\text { Espourteille \& Fleischer } 1988 . \\
\text { Fleischer \& Espourteille } 1998\end{array}$ \\
\hline $\mathrm{Pb}, \mathrm{Zn}, \mathrm{Ag}$ & Nova Redenção (BA) & Mississippi Valley & $600-650(\mathrm{p})$ & Misi et al. 1998 \\
\hline $\mathrm{Pb}, \mathrm{Zn}, \mathrm{Ag}$ & Serra do Ramalho (BA) & Mississippi Valley & $600-650(p)$ & Misi et al. 1998 \\
\hline $\mathrm{Pb}, \mathrm{Zn}, \mathrm{Ag}$ & Caboclo (BA) & Mississippi Valley & $1200(\mathrm{I})$ & Misi e t al. 1998 \\
\hline $\mathrm{Sn}, \mathrm{Ta}$ & $\begin{array}{l}\text { Pedra Branca (granito } \\
\text { Mangabeira) (GO) }\end{array}$ & $\begin{array}{l}\text { Cassiterita em greisens e } \\
\text { pegmatitos. Placers aluviais. }\end{array}$ & $\begin{array}{c}1425-1535(P) \\
\text { U-Pb em cassiterita }\end{array}$ & $\begin{array}{l}\text { Botelho \& Rossi } 1988 . \\
\text { Sparrenberger \& Tassin ari } \\
1998 .\end{array}$ \\
\hline $\mathrm{Sn}, \mathrm{Ta}$ & $\begin{array}{l}\text { Xupé e Riacho dos Cavalos } \\
\text { (GO) }\end{array}$ & Greisens e pegmatitos & $\begin{array}{c}2023-2277(\mathrm{P}) \\
\text { U-Pb em cassiterita } \\
\end{array}$ & $\begin{array}{l}\text { Sparrenberger \& Tassinari } \\
1998 .\end{array}$ \\
\hline $\begin{array}{l}\mathrm{Sn}, \mathrm{W}, \mathrm{Ta}, \\
\mathrm{Nb}\end{array}$ & $\begin{array}{l}\text { Grupo de depósitos da suite } \\
\text { Serra da Providên-cia (RO) }\end{array}$ & $\begin{array}{l}\text { Cassiterita em greisens e } \\
\text { pegmatitos. Placers aluviais. }\end{array}$ & $\begin{array}{c}\text { Pegmatitos (granitos)1554-1606 (U- } \\
\text { Pb em zircão) (P). } \\
\text { Placers-0,2-2 (P) }\end{array}$ & $\begin{array}{l}\text { Bettencourt et al. } 1988 . \\
\text { Carvalho 1988. Tosdal et al. } \\
1996\end{array}$ \\
\hline $\begin{array}{l}\mathrm{Sn}, \mathrm{W}, \mathrm{Ta}, \\
\mathrm{Nb}\end{array}$ & $\begin{array}{l}\text { Grupo de depósitos da suite } \\
\text { Santo Antônio (RO) }\end{array}$ & $\begin{array}{l}\text { Cassiterita em greisens e } \\
\text { pegmatitos. Placers aluviais. }\end{array}$ & $\begin{array}{c}\text { Pegmatitos (granitos) 1387-1406 (U- } \\
\text { Pb em zircão) (P). } \\
\text { Placers-0,2-2 (P) }\end{array}$ & $\begin{array}{l}\text { Bettencourt et al. } 1988 . \\
\text { Carvalho 1988. Tosdal } \\
1996\end{array}$ \\
\hline $\begin{array}{l}\text { Sn, W, Ta, } \\
\text { Nb }\end{array}$ & $\begin{array}{l}\text { Grupo de depósitos da suite São } \\
\text { Lourenço-Caripunas (RO) }\end{array}$ & $\begin{array}{l}\text { Cassiterita em greisens e } \\
\text { pegmatitos. Placers aluviais. }\end{array}$ & $\begin{array}{c}\text { Pegmatitos (granitos)1314-1309 (U- } \\
\text { Pb em zircão) (P). } \\
\text { Placers-0,2-2 (P) }\end{array}$ & $\begin{array}{l}\text { Bettencourt et al. } 1988 . \\
\text { Carvalho 1988. Tosdal } \\
1996\end{array}$ \\
\hline $\begin{array}{l}\text { Sn, W, Ta, } \\
\mathrm{Nb}\end{array}$ & Igarapé Preto (AM) & $\begin{array}{l}\text { Cassiterita em greisens e } \\
\text { pegmatitos. Placers aluviais. }\end{array}$ & $\begin{array}{l}\text { Pegmatitos (granitos)1314-1309 (U. } \\
\text { Pb em zircão) (P). } \\
\text { Placers- 0,2-2 (P) }\end{array}$ & $\begin{array}{l}\text { Veiga } 1988 \text { (b). Tosdal et al. } \\
1996\end{array}$ \\
\hline $\mathrm{Sn}, \mathrm{Ta}$ & $\begin{array}{l}\text { Grupo de depósitos de Potosi, } \\
\text { Oriente Novo, Pedra Branca } \\
\text { (RO) }\end{array}$ & $\begin{array}{l}\text { Greisen e palcers aluviais e } \\
\text { coluviais. }\end{array}$ & $\begin{array}{c}\text { Pegmatitos-998-1081 (P) } \\
\text { Greisen- } 950 \pm 50(\mathrm{P}) \\
\text { Placers- } 0,2-2(\mathrm{P}) \\
\end{array}$ & $\begin{array}{l}\text { Bettencourt et al. } 1988 . \\
\text { Carvalho 1988. Tosdal } \\
1996\end{array}$ \\
\hline $\begin{array}{l}\text { Sn, Nb, Ta, } \\
\text { TR }\end{array}$ & Pitinga (AM) & $\begin{array}{l}\text { Greisen, apogranito e placers } \\
\text { aluviais e coluviais. }\end{array}$ & $\begin{array}{c}\text { Greisen-1689 } 19(\mathrm{P}) \\
\text { Placers- } 0,2-2(\mathrm{P}) \\
\end{array}$ & El Koury \& Antonietto Jr. 1988 \\
\hline $\begin{array}{l}\mathrm{Sn}, \mathrm{W}, \mathrm{Ta} \\
\mathrm{Nb}\end{array}$ & São Francisco (MT) & $\begin{array}{l}\text { Placeres aluviais derivados de } \\
\text { pegmatitos e greisens. }\end{array}$ & $\begin{array}{c}\text { Pegmatitos (granitos) } 998-1606 \text { (U- } \\
\text { Pb em zircão) (P). } \\
\text { Placers- } 0,2-2 \text { (P) } \\
\end{array}$ & $\begin{array}{l}\text { Veiga 1988. Tosdal et al. } 1996 . \\
\text { Delgado \& Pedreira } 1994\end{array}$ \\
\hline Sn & São Pedro do Iriri (PA) & $\begin{array}{l}\text { Placers aluviais derivados de } \\
\text { pegmatitos e greisens. }\end{array}$ & Placers $0,2-2(\mathrm{P})$ & Barbosa et al. 1988 \\
\hline $\mathrm{Sn}$ & Surucucus (RR) & Greisens e apogranitos & $1500-1800(\mathrm{I})$ & Delgado \& Pedreira 1994 \\
\hline $\begin{array}{l}\text { Terras } \\
\text { Raras, } \mathrm{P}\end{array}$ & Barra do ltapirapuã (SP-PR) & $\begin{array}{l}\text { Bastnaesita-sinchisita em } \\
\text { carbonatitos }\end{array}$ & $100-110(\mathrm{P})$ & Ruberti et al. 1997 \\
\hline $\begin{array}{l}\text { Terras } \\
\text { Raras, Th }\end{array}$ & Catalão I (GO) & $\begin{array}{l}\text { Enriquecimento residual de } \\
\text { monazita e florencita sobre } \\
\text { carbonatitos. }\end{array}$ & $\begin{array}{c}\text { Carbonatitos-82,9(K-Ar) }(\mathrm{P}) \\
\text { Enriquecimento residual-55-0 (P) }\end{array}$ & Hasui \& Cordani 1962 \\
\hline $\begin{array}{l}\text { Terras } \\
\text { Raras, Th }\end{array}$ & Guarapari (ES) & Placer marinho & $<1(P)$ & \\
\hline Talco & Itaiacoca (PR) & $\begin{array}{l}\text { Metamorfismo e } \\
\text { hidrotermalismo sobre } \\
\text { dolomitos. }\end{array}$ & $550-600(\mathrm{p})$ & \\
\hline
\end{tabular}


Tabela l-Continuação

\begin{tabular}{|c|c|c|c|c|}
\hline MINÉRIO & $\begin{array}{c}\text { NOME DO } \\
\text { DEPÓSITO } \\
\text { (Estado) }\end{array}$ & $\begin{array}{l}\text { MODELO GENETICO } \\
\text { PROVAVEL }\end{array}$ & $\begin{array}{l}\text { DADE DA MINERALZAÇĀO } \\
(\text { Min - Max }) \\
(\mathrm{Ma})\end{array}$ & REFERENCLA \\
\hline Ti & Catalāo I (GO) & $\begin{array}{l}\text { Enriquecimento residual sobre } \\
\text { carbonatitos. }\end{array}$ & & \\
\hline $\mathrm{Ti}, \mathrm{Zr}, \mathrm{Th}$ & Săo Joảo da Barra (RJ) & Placers marinhos. & $2-0(\mathrm{P})$ & Deigado \& Pedreira 1994 \\
\hline $\mathbf{T i}, \mathbf{P}$ & Patrocínio (MG) & $\begin{array}{l}\text { Enriquecimento residual sobre } \\
\text { rochas alcalinas. }\end{array}$ & $\begin{array}{c}\text { Rochas alcalinas-82 } \\
\text { (K-Ar) (P) } \\
\text { Enriquecimento residual-2-0 (P) }\end{array}$ & Hasui \& Cordani 1962 \\
\hline $\mathrm{Ti}, \mathrm{ZT}, \mathrm{Th}$ & Brejo Grande (SE) & Placers marinhos. & $2-0(\mathrm{P})$ & Delgado \& Pedreira 1994 \\
\hline $\mathrm{Ti}, \mathbf{Z r}$ & Mataraca (RN, PB) & Placers marinhos. & $2-0(\mathrm{P})$ & Delgado \& Pedreira 1994 \\
\hline $\mathrm{Ti}, \mathrm{V}, \mathrm{Fe}$ & Campo Alegre de Lourdes (BA) & $\begin{array}{l}\text { Depósitos tipo Adirondack } \\
\text { (Allard Lake), relacionados a } \\
\text { anortositos. }\end{array}$ & $2000-2200$ (I) & $\begin{array}{l}\text { Sampaio et al. 1986. Delgado } \\
\text { \& Pedreita 1994. Schobbenhaus } \\
\& \text { Campos } 1984\end{array}$ \\
\hline Topa-zio & Massangana (RO) & Depósitos tipo greisen. & $998-1080(\mathrm{P})$ & $\begin{array}{l}\text { Rodrigues 1991. Tosdal et al. } \\
1996\end{array}$ \\
\hline Topa-zio & Ouro Preto (MG) & $\begin{array}{l}\text { Filóes em fraturas que cortam } \\
\text { rochas carbonatadas. }\end{array}$ & $550-600(\mathrm{p})$ & Ferreira 1991. Bello et al. 1995 \\
\hline $\begin{array}{l}\text { Tourma- } \\
\text { lina }\end{array}$ & Galileia (MG) & Pegmatitos & $460-470(\mathrm{P})$ & Nalini Jr. et al. 1996 \\
\hline $\mathrm{U}(\mathrm{Mo})$ & Figueira (PR) & Sedimentar pós-diagenético. & $225-250(\mathrm{P})$ & Morrone \& Daemon 1985 \\
\hline$\overline{\mathrm{U}}$ & Campos Belos e Rio Preto (GO) & $\begin{array}{l}\text { Uraninita e sulfetos em } \\
\text { xistosidade e fraturas (Zona de } \\
\text { cisalhamento?). }\end{array}$ & 2000 (I) & Andrade ef al. 1985 \\
\hline $\mathbf{U}$ & $\begin{array}{l}\text { Lagoa Real (BA) } \\
\text { : }\end{array}$ & U em episienitos. & $820(\mathrm{~Pb}-\mathrm{Pb})(\mathrm{P})$ & Oliveira et al. 1985. \\
\hline $\mathrm{U}$ & Espinharas (PB) & $\mathrm{U}$ in episienitos & $395-450(\mathbf{P})$ & Santos \& Anacleto 1985. \\
\hline $\mathrm{U}$ & Amorinópolis (GO) & Depósitos tipo rolo (Roll type). & $390(\mathbf{P})$ & Hassano 1985 \\
\hline $\mathrm{U}, \mathrm{Au}$ & Moeda (MG) & Paleoplacers tipo Witwtersrand. & $\begin{array}{c}2420-2606 \\
\text { (Pb-Pb, U-Pb, laser ablation em } \\
\text { zircão) (P) }\end{array}$ & $\begin{array}{l}\text { Villaça \& Moura } 1985 . \\
\text { Machado et al. 1996. Babinski } \\
\text { et al. } 1995\end{array}$ \\
\hline $\mathbf{U}, \mathbf{P}$ & Itataia $(C E)$ & $\begin{array}{l}\text { 1. Fosforitas uraníferas } \\
\text { encaixadas por gneisses. } \\
\text { 2. Epissienitização de gneisses. } \\
\text { 3. Enriquecimento supergêrico. }\end{array}$ & $\begin{array}{l}\text { 1. Fosforitas-2000-2500 (I) } \\
\text { 2. Epissienitos- } 550-600(\mathrm{p}) \\
\text { 3.Enriquecimento supergê- } \\
\text { nico }<50(?)(\mathrm{l})\end{array}$ & Mendonça et al. 1985 \\
\hline $\begin{array}{l}\text { U, Mo, Zr, } \\
\text { TR }\end{array}$ & Osamu Utsumi (Cercado) (MG) & $\begin{array}{l}\text { 1. Veios de fluidização e } \\
\text { disserninação hidrotermal dos } \\
\text { elementos do minerio. } \\
\text { 2. Enriquecimento associado a } \\
\text { front de oxidaçăo. }\end{array}$ & $60-87(\mathrm{P})$ & Fraenkel et al. 1985. \\
\hline $\mathrm{V}, \mathrm{Ti}, \mathrm{Fe}$ & Fazenda Gulçari (BA) & $\begin{array}{l}\text { Depósitos tipo Adirondack. } \\
\text { relacionados a anortositos. }\end{array}$ & $2000-2200$ (I) & $\begin{array}{l}\text { Galväo et al. } 1986 . \\
\text { Delgado \& Pedreira } 1994\end{array}$ \\
\hline Vermiculita & Paulistana (BA) & & & \\
\hline$\overline{\mathrm{W}}$ & Cerro da Catinga (SC) & $\begin{array}{l}\text { Filoes hidrotermais } \\
\text { pneumatolíticos, com } \\
\text { wolframita, relaci onados a } \\
\text { granitos. }\end{array}$ & $\begin{array}{l}647(\mathrm{U}-\mathrm{Pb})(\mathrm{P}) \\
622(\mathrm{Rb}-\mathrm{Sr})(\mathrm{P})\end{array}$ & $\begin{array}{l}\text { da Silva et al. } 1986 . \\
\text { Castro } 1997\end{array}$ \\
\hline W(Mo) & $\begin{array}{l}\text { Brejui, Barra Verde, Barro } \\
\text { Vermelho, Boca do Lage, } \\
\text { Zangarelhas (RN) }\end{array}$ & $\begin{array}{l}\text { Minério escarnítico com } \\
\text { scheelita. }\end{array}$ & $550-600(p)$ & $\begin{array}{l}\text { Maranhăo et al. 1986. Salim et } \\
\text { al. } 1996\end{array}$ \\
\hline $\mathbf{W}$ & Pedra Preta (PA) & $\begin{array}{l}\text { Filoes hidrotermais de quartzo } \\
\text { com wolframita. }\end{array}$ & $1883(\mathrm{U}-\mathrm{Pb})(\mathrm{P})$ & $\begin{array}{l}\text { Cordeiro \& da Silva } 1986 . \\
\text { Macambira et al. } 1996 .\end{array}$ \\
\hline $\mathrm{Zn}, \mathrm{Pb}$ & Morro Agudo (MG) & $\begin{array}{l}\text { Cimentação diagenética de } \\
\text { rochas carbonatadas. Tipo } \\
\text { Mississippi Valley irlandes? }\end{array}$ & 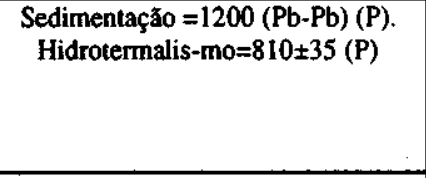 & $\begin{array}{l}\text { Schobbenhaus \& Campos } 1984, \\
\text { Romagna \& Costa 1988. Iyer } \text { et } \\
\text { al. } 1992 \text {, Freitas-Silva } \\
\text { Dardenne 1997. Oliveira } 1998 . \\
\text { Dardenne \& Freitas-Silva } 1998 \\
\end{array}$ \\
\hline $\mathrm{Zn}, \mathrm{Pb}, \mathrm{Cd}$ & Vazante (MG) & $\begin{array}{l}\text { 1. Filöes primários hidrotermais } \\
\text { com willemita } \\
\text { 2. Depósito secundário com } \\
\text { calamina supergênica }\end{array}$ & $\begin{array}{c}\text { 1.Filöes primá- } \\
\text { rios-1000-1200 (Pb-Pb) (P). } \\
\text { 2.Enriquecimento supergênico-600- } \\
750(680 \text { ?) (P) }\end{array}$ & $\begin{array}{l}\text { Schobbenhaus \& Campos } \\
\text { 1984. Rigobello et al. } 1988 . \\
\text { lyer et al. 1992. Freitas-Silva \& } \\
\text { Dardenne 1997. Oliveira } 1998 . \\
\text { Dardenne \& Freitas-Silva } 1998\end{array}$ \\
\hline $\mathrm{Zn}, \mathrm{Cu}, \mathrm{Pb}$ & Palmeitó-polis (GO) & $\begin{array}{l}\text { Depósito vulcanogênico tipo } \\
\text { Besshi }\end{array}$ & $\begin{array}{c}2000-2500(\mathrm{~B}) \\
>950(\mathrm{~K}-\mathrm{Ar})(\mathrm{I})\end{array}$ & $\begin{array}{l}\text { Schobbenhaus \& Campos } 1984 . \\
\text { Araujo \& Nilson } 1988 .\end{array}$ \\
\hline
\end{tabular}


idades dos filões auríferos da mina de Passagem de Mariana (20672093 Ma, Schrank e Machado 1996), da bacia aurífera de Jacobina (1900-2080, Mougeot et al. 1996), da mineralização de ouro na Fazenda Brasileiro (2031-2083 Ma, Xavier et al. 1994), da mineralização de Cu da Mina de Camaquã (560-590 Ma, Remus et al. 1997, Biondi 1997), do kimberlito mineralizado a diamante de Paranatinga (121 Ma, Tompkins \& Gonzaga 1989) e a idade dos depósitos de bauxita associadas à superfície de aplainamento sul-americana (55-2 Ma, Schobbenhaus \& Coelho 1986), entre outros. Na tabela, idades consideradas prováveis estão identificadas pelo símbolo $(\mathrm{P})$ grafado logo após a idade.

2. Idade possível: Nessa categoria foram enquadradas as idades ou intervalo de idades de depósitos cujos processos mineralizadores são conhecidos e definidos: (a) por meio de datação de rochas correlacionadas ao depósito mineral, (b) ou por datacões consideradas não definitivas pelos seus autores, (c ) ou por correlação com fenómenos geológicos cujas idades foram determinadas em local ou região que não a do depósito mineral. Como exemplo podem ser citadas as idades dos pegmatitos com água marinha e dos depósitos de talco da Formação Itaiacoca (PR), formados durante o Brasiliano (500-550 Ma, Schobbenhaus \& Coelho 1992, Delgado \& Pedreira 1994), a idade da mineralização de cobre em Caraíba (2250 Ma, D'El Rey Silva \& Oliveira 1998), as idades dos depósitos filonianos de $\mathrm{Pb}$ do Vale do Ribeira (Daitx 1996) e a idade do depósito de U (Mo) de Figueira, PR (Permiano, entre 225 e $250 \mathrm{Ma}$, Schobbenhaus 1985), entre outros. Na tabela, idades consideradas possíveis estão identificadas pelo símbolo (p) grafado logo após o resultado da datação.

3.ldade indicada: Nessa categoria foram enquadradas as idades, ou intervalos de idades, mal definidos (intervalos muito largos) devido a insuficiência em datações das mineralizações e das rochas dos depósito. Nesse caso as idades foram inferidas por correlação com fenómenos geológicos cujas idades abrangem um período extenso do tempo geológico. Na tabela, idades consideradas indicadas estão identificadas pelo símbolo (I) grafado logo após o resultado da datação. A classificacão das idades das mineralizações improvável, possível $e$ indicada foi feita com uma precisão que considera a possibilidade de uma dada idade situar-se dentro de um intervalo de 50 Ma correspondente ao resultado da datação.

Agradecimentos A dois revisores anônimos da RBG pelas sugestões e valiosas críticas.

\section{Referências}

Aciari Jr. D., Ribeiro J.C. Dias J.R.M., Brandão W. 1988. Mina de chumbo e prata do Rocha, Adrianópolis, Paraná. Principais Depósitos Minerais Brasileiros - Metais Básicos Não Ferrosos, Ouro e Alumínio. DNPM, Vol. 3, 135-145.

Alves, C.A. Bernardelli A.L., Beisiegel V.R. 1986. A jazida de níquel laterítico do Vermelho, Serra dos Carajás, Goiás. In: Principais Depósitos Minerais Brasileiros - Ferro e Metais da Indústria do Aco. DNPM, Vol. 2, 325-334.

Amaral E.V., Farias N.F., Saueressig R., Viana Júnior A., Andrade V.L.M., 1988. Jazida de cobre Salobo 3 A e 4 A, Serra dos Carajás, Pará. Principais Depósitos Minerais Brasileiros-Metais Básicos Não Ferrosos, Ouro e Alumínio. DNPM, vol. 3,43-53.

Andrade F.G., Nakashima J., Podestá P.R. 1986. Depósito de manganês da Serra do Burítirama, Pará. In: Principais Depósitos Minerais Brasileiros - Ferro e Metais da Indústria do Aço. DNPM, Vol. 2, 153-166.

Andrade S.M., Liberal G.S., Santos Filho J.L. 1985. Depósito de urânio de Campos Belo e Rio Preto. Principais Depósitos Minerais Brasileiros - Recursos Minerais Energéticos. DNPM, Vol. 1, 169-175.

Arantes D., Osborne G.A., Buck P.S., Porto C.G. 1991. The Mara Rosa volcano-sedimentary sequence and associated gold mineralization. In: E.A. Ladeira (ed.) Brazil Gold' 91. Anais, 221-229.

Araújo S.M. \& Nilson A.A. 1988. Depósito de zinco, cobre e chumbo de Palmeirópolis, Goiás. 1988. Principais Depósitos Minerais Brasileiros - Metais Básicos Não Ferrosos, Ouro e Alumínio. DNPM, Vol. 3, 171-180.

Babinski M., Chemale Jr. F., Van Schmus W.R. 1995. The Pb/Pb age of Minas Supergroup carbonate rocks, Quadrilátero Ferrífero, Brazil. Precambrian Research, 72:235-245.

Badi W.S.R. \& Gonzalez A.P. 1988. Jazida de metais básicos de Santa Maria, Caçapava do Sul, Rio Grande do Sul. Principais Depósitos Minerais Brasileiros - Metais Básicos Não Ferrosos, Ouro e Alumínio. DNPM, Vol. 3, 157-170.

Baeta Júnior J.d. A. 1986. As jazidas de níquel laterítico de Barro Alto, Goiás. In -Principais Depósitos Minerais Brasileiros - Ferro e Metais da Indústria do Aço. DNPM, Vol. 2,315-323.

Bandeira S.A.B., Morelli S., Mello C.S.B., Moraes R.A.V.1986. Depósitos "stratabound" de barita da Fazenda Barra, bacia sedimentar do Recôncavo/Tucano (BA). In SBG Congresso Brasileiro de Geologia, 34, Goiânia, Anais, 5:2229-2240.

Barbosa E.P., Lorenzi V.E., Ojima S.K. 1988. Jazida de cassiterita de São Pedro do Iriri, Pará. Principais Depósitos Minerais Brasileiros - Metais Básicos Não Ferrosos, Ouro e Alumínio. DNPM, Vol. 3, 261-265.

Barcelos J.P. \& Buchi J. (a). 1986. Mina de minério de ferro de Alegria, Minas Gerais. In -.Principais Depósitos Minerais Brasileiros - Ferro e Metais da Indústria do Aço. DNPM, Vol. 2,77-85

Barcelos J.P. \& Buchi J.(b). 1986. Mina de minério de ferro-manganês de Miguel Congo, Minas Gerais. In -.Principais Depósitos Minerais Brasileiros - Ferro e Metais da Indústria do Aço. DNPM, Vol. 2, 87-95.

Basílio J.A.F. \& Brondi M.A. 1986. Distrito manganesífero da região de Licínio de Almeida, Bahia. In -.Principais Depósitos Minerais Brasileiros - Ferro e Metais da Indústria do Aço. DNPM, Vol. 2, 177-185.

Bastos J.B.S. 1988. Depósito de ouro do Rio Madeira, Rondônia. In: Schobbenhaus C. Coelho C.E.S. (Eds.), 1988. Principais Depósitos Minerais Brasileiros - Metais Básicos Não Ferrosos, Ouro e Alumínio. DNPM, Vol. 3, 575-588.

Bastos Neto A., Touray J-C, Dardenne M., Charvet J. 1991. Chronologie et évolution des fluides hydrothermaux dans le district à fluorine de Santa Catarina, Brésil: Donnés de 1'analyse des terres rares et de 1'étude des inclusions fluides. Mineralium Deposita, 26:211-216.

Bello R.M.S., Gandini A.L., Fuzikawa K., Svisero D.P. 1995. Estudo microtermométrico de inclusões fluidas do topázio imperial da jazida Boa Vista, Ouro Preto, MG. Revista da Escola de Minas, Ouro Preto, 49(2): 111-116.

Berbert C.O. 1986. O depósito de níquel laterítico de Morro do Engenho, Goiás. In -.Principais Depósitos Minerais Brasileiros - Ferro e Metais da Indústria do Aço. DNPM, Vol. 2, 335-340

Bettencourt J.S., Muzzzolon R., Payolla B.L., Dall Igna L.G., Pinho O.G. 1988. Depósitos estaníferos secundários da região central de Rondônia. Principais Depósitos Minerais Brasileiros - Metais Básicos Não Ferrosos, Ouro e Alumínio. DNPM, Vol. 3,213-241.
Biondi J.C. \& Furtado L.I. 1999. Geologia e génese dos depósitos de caulim Floresta e Cambuí (Formação Campo Alegre - SC): 1. Faciologia e mineralogia das rochas e minérios. Revista Brasileira de Geociência, 29(1) (no prelo)

Biondi J.C. \& Poidevin J-L. 1994. L'âge de Ia mineralisation des depôts d'émeraudes de SantaTerezinha(Goiás-Brésil). Comunicaciones-Universidad de Chile, 45:33-44.

Biondi J.C. 1972. Depósitos de manganês da região de Urandi e Licínio de Almeida, Bahia. Relatório interno da MINERAÇÃO URANDI S.A., inédito, 24 p.

Biondi J.C. 1997. Idade das alterações hidrotermais associadas às mineralizações da Mina Uruguai, Camaquã - RS. Relatório ao CNPq-PADCT. Inédito, 3 p.

Biondi J.C. 1999. Geologia e génese dos depósitos de caulim Florestae Cambuí (Formação Campo Alegre - SC): 2. Petroquímica e modelo genético. Revista Brasileira de Geociência, 29(1) (no prelo).

Bomfim L.F.C. 1986. Fosfato de Irecê (BA): Um exemplo de mineralização associada a estromatólitos do Pré-Cambriano Superior. In SBG, Congresso Brasileiro de Geologia, 34, Goiânia, Anais, 5:2154-2167.

Bonow C.W. \& Issler R.S. 1980. Reavaliação e aspectos económicos do jazimento de terras raras e ferro-ligas do Lago Esperança, Complexo carbonatítico de Seis Lagos Amazonas, Brasil. In: SBG, Congresso Brasileiro de Geologia, 31, Camboriu, Anais, 3:1431

Botelho N.F. \& Rossi G. 1988. Depósito de estanho da Pedra Branca, Nova Roma, Goiás. Principais Depósitos Minerais Brasileiros - Metais Básicos Não Ferrosos, Ouro e Aluminio. DNPM, Vol. 3, 267-285.

Braga J.B.P. \& da Silva Alves C. A. 1988. Depósitos de bauxita refratária do Pará e Amapá In: Schobbenhaus C., Coelho C.E.S. (Eds.), 1988. Principais Depósitos Minerais Brasileiros - Metais Básicos Não Ferrosos, Ouro e Alumínio. DNPM, Vol. 3 , 642-653.

Brizzi A.S. \& Roberto F.A.C. 1988. Jazida de cobre de Pedra Verde - Viçosa do Ceará, Ceará. In: Schobbenhaus C., Coelho C.E.S. (Eds.), 1988. Principais Depósitos Minerais Brasileiros - Metais Básicos Não Ferrosos, Ouro e Alumínio. DNPM, Vol. 3:71-80.

Carvalho Filho A. R., Queiroz E.T., Leahy G. A.S. 1986. Jazida de cromita de Pedras Pretas, Município de Santa Luz, Bahia. In - Principais Depósitos Minerais Brasileiros Ferro e Metais da Indústria do Aço. DNPM, Vol. 2, 235-248.

Carvalho M.S. Akabane T. Tesser M.A., Filho, L.T. da S. 1991. Depósito de diamante da Fazenda camargo, Nortelândia, Mato Grosso. Principais Depósitos Minerais Brasileiros - Gemas e Rochas Ornamentais. DNPM, Vol. 4,161-176.

Carvalho R.T. 1988. Depósitos de cassiterita de Santa Bárbara, Jacundá e Alto Candeias, Rondônia. Principais Depósitos Minerais Brasileiros - Metais Básicos Não Ferrosos, Ouro e Alumínio. DNPM, Vol. 3, 243-253.

Cassedane J.P. \& Sauer D.A.1988. Classification of gemstone deposits in Brazil. Revista da Escola de Minas de Ouro Preto, vol. 33:7-20.

Castro Filho L.W. \& Mattos S.C. 1986. Depósito de níquel laterítico de Jacaré e Jacarezinho, Município de São Felix do Xingu, Pará. In -.Principais Depósitos Minerais Brasileiros - Ferro e Metais da Indústria do Aço. DNPM, Vol. 2,369-384

Castro N. A. 1997. Contribuição ao conhecimento geológico-metalogenético associado aos granitóides intrusivos no Grupo B rusgue (SC) com base em informações geológicas, aerogamaespectrometricas e Landsat/TM-5. Instituto de Geociências - UNICAMP, Tese de Mestrado, 139 p., apêndice e mapas.

Chaves M.L.S.C. \& Uhlein A. 1991. Depósitos diamantíferos da região do alto/médio Rio Jequitinhonha, Minas Gerais. Principais Depósitos Minerais Brasileiros - Gemas e Rochas Ornamentais. DNPM, Vol. 4, 117-138.

Coelho C.E.S. 1986. Depósito de ferro da Serra dos Carajás, Pará In - Principais Depósitos Minerais Brasileiros - Ferro e Metais da Indústria do Aço. DNPM, Vol. 2, 29-64.

Coelho C.E.S. \& Rodrigues O.B. 1986. Jazida de manganês do Azul, Serra dos Carajás, Pará. In -.Principais Depósitos Minerais Brasileiros - Ferro e Metais da Indústria do Aço. DNPM, Vol. 2,145-152.

Coelho C.E.S., Jost H., Valle R.R., Dardenne M.A. 1986. O controle estrutural dos depósitos de fluorita do Distrito de Tanguá - Rio de Janeiro. In SBG, Congresso Brasileiro de Geologia, 34, Goiânia, Anais, 5:2089-2104.

Collyer T.A, Machado J.I.L., Pinto R.G. 1990. Potencial gemológico do Estado do Pará In SBG, Congresso Brasileiro de Geologia, 36, Natal, Anais, 3:1425-1435. 
Collyer T.A. \& Mártires R.A.C. 1986. O depósito de ametista do Alto Bonito, Município de Marabá, Pará. In SBG, Congresso Brasileiro de Geologia, 34, Goiânia, Anais, 5:2221-2228.

Collyer T.A., Mártires R.A.C., Machado J.I.L. 1981.0 depósito de ametista de PauD'Arco, Município de Conceição do Araguaia, Pará. Principais Depósitos Minerais Brasileiros - Gemas e Rochas Ornamentais. DNPM, Vol. 4, 295-302.

Collyer, T.A., Mártires, R.A.C. 1981. O depósito de ametista do alto bonito, Município de Marabá, Pará. Principais Depósitos Minerais Brasileiros - Gemas e Rochas Ornamentais. DNPM, Vol. 4, 287-293.

Cordeiro A.A.C. \& da Silva A. V. 1986. Depósito de wolframita da região de Pedra Preta, Pará. In :Principais Depósitos Minerais Brasileiros - Ferro e Metais da Indústria do Aço. DNPM, Vol. 2, 409-415.

Costa E.D.A. 1991. Depósitos alúvio-diamantíferos da Chapada Diamantina, Bahia. Principais Depósitos Minerais Brasileiros - Gemas e Rochas Ornamentais. DNPM, Vol. 4, 199-208.

Costa S. A.G. \& Sá W.L. 1991. Garimpes de esmeralda de Santa Terezinha de Goiás, Goiás. Principais Depósitos Minerais Brasileiros - Gemas e Rochas Ornamentais. DNPM, Vol. 4, 245-258.

Coura F., Moeri E.N., Kern R.S. 1986. Geologia do caulim do Jari. In SBG, Congresso Brasileiro de Geologia, 34, Goiânia, Anais, 5:2248-2258.

Couto P. A., Silva E.A., Lima R. 1991. Garimpes de esmeralda de CarnaíbaeSocotó, Bahia. Principais Depósitos Minerais Brasileiros - Gemas e Rochas Ornamentais. DNPM, Vol. 4, 259-269.

Cruz F.F., Brenner T.L., Moreira A.F.S., Cunha C A.B.R Gálio C.B.M., Franke N.D, Pimentel R.C. 1986. Jazida de Ni-Cu-Co de Fortaleza de Minas, Minas Gerais. In Principais Depósitos Minerais Brasileiros - Ferro e Metais da Indústria do Aço. DNPM, Vol. 2, 275-306.

D'E1 Rey Silva L.J.H. \& Oliveira J.G. 1998. Geology of the Caraíba copper mine and its surroudings in the paleoproterozoic Curaça Belt - Curaça River Valley, Bahia, Brazil. In Misi e Glória da Silva (Ed.) Workshop: Depósitos Minerais Brasileiros de Metais-Base. Anais, 21-28.

D'E1 Rey Silva L.J.H., 1985. Geologia e controle estrutural do depósito cuprífero de Caraíba, Vale do Curaça- Bahia. Geologia e Recursos Minerais do Estado da Bahia - Textos Básicos, 6:51 -124.

da Silva A.B. 1986. Jazida de nióbio de Araxá, Minas Gerais. In Principais Depósitos Minerais Brasileiros - Ferro e Metais da Indústria do Aço. DNPM, Vol. 2435-453.

da Silva A.B., Liberal G.S., Issa Filho A., Rodrigues, C.S., Riffel B.F. 1987. Depósito de fosfato em carbonatito do Pré-Cambriano - Angico dos Dias, BA.. Relatório interno da $C B M M$, Inédito, $8 \mathrm{p}$.

da Silva C.R., Souza I.M., Brandão W. 1988. Mina de chumbo e prata do Perau, Adrianópolis, Paraná. Principais Depósitos Minerais Brasileiros - Metais Básicos Não Ferrosos, Ouro e Alumínio. DNPM, Vol. 3, 123-134.

da Silva M.A.S., Camozzato E., Krebs A.S.J., da Silva L.C. 1986. Depósito de wolframita de Cerro da Catinga, Nova Trento, Santa Catarina. In '.Principais Depósitos Minerais Brasileiros - Ferro e Metais da Indústria do Aço. DNPM, Vol. 2,417-426.

Daitx E. 1996. Origem e evolução dos depósitos sulfetados tipo Perau (Pb-Zn-Ag), com base nas jazidas Canoas e Perau (Vale do Ribeira, PR). UNESP, Tese de Doutorado, $354 \mathrm{p}$.

Dardenne M.A. \& Freitas-Silva F.H. 1998. Modelos genéticos dos depósitos Pb-Zn nos Grupos Bambui e Vazante. In: Depósitos Minerais Brasileiros de Metais-Base, Workshop, Extended Abstracts, 86-93.

de Ferran A. 1988. Depósito de ouro de Salamangone e Mutum, Calçoene, Amapá. In: Schobbenhaus C. , Coelho C.E.S. (Eds.), 1988. Principais Depósitos Minerais Brasileiros - Metais Básicos Não Ferrosos, Ouro e Alumínio. DNPM, Vol. 3 , 581-588.

de Ferran A. 1988. Mina de ouro de São Francisco, Currais Novos, Rio Grande do Norte. In: Schobbenhaus C., Coelho C.E.S. (Eds.), 1988. Principais Depósitos Minerais Brasileiros - Metais Básicos Não Ferrosos, Ouro e Alumínio. DNPM, Vol. 3 , Brasileiros

Delgado LM. \& Pedreira A.J. 1994. Síntese da Evolução Geológica do Brasil. CPRM-Companhia de Pesquisa de Recursos Minerais - Publicação Especial, 27 p., 4 mapas,

do Rego J.M. 1981. Depósito de água marinha da região de Tenente Ananias, rio Grande do Norte. Principais Depósitos Minerais Brasileiros - Gemas e Rochas Ornamentais. DNPM, Vol. 4, 327-336.

Duarte P.M. \& Fontes C.F. 1986. Minas de cromita das Fazendas Limoeiro e Pedrinhas, Município de Campo Formoso, Bahia. In Principais Depósitos Minerais Brasileiros - Ferro e Metais da Indústria do Aço. DNPM, Vol. 2, 207-214.

Dupont H. 1991. Jazida aluvionar de diamante do Rio Jequitinhonha, em Minas Gerais. Principais Depósitos Minerais Brasileiros - Gemas e Rochas Ornamentais. DNPM, Vol. 4, 139-148.

El Koury W. \& Antonietto Jr. A. 1988. Mina de estanho de Pitinga, Amazonas. Principais Depósitos Minerais Brasileiros - Metais Básicos Não Ferrosos, Ouro e Alumínio. DNPM, Vol. 3, 201-211.

Espourteille F. \& Fleischer R. 1988. Mina de chumbo de Boquira, Bahia. Principais Depósitos Minerais Brasileiros - Metais Básicos Não Ferrosos, Ouro e Alumínio. DNPM, Vol. 3, 91-99.

Ferreira C.M. 1991. Topázio de Ouro Preto, Minas Gerais. Principais Depósitos Minerais Brasileiros - Gemas e Rochas Ornamentais. DNPM, Vol. 4, 303-308.

Ferreira Filho C.F. \& Danni J.C.M. 1985. Petrologia e mineralizações sulfetadas do prospecto Bahia - Carajás. In: Simpósio de Geologia da Amazónia, Anais, 2, 3:34-47.

Figueiredo B., Réquia K., Xavier R. 1994. Post-depositional changes of the Salobo ore deposit, Carajás Province, northern Brazil. Comunicaciones-Universidad de Chile, 45:23-32.

Fleischer R. \& Espourteille F.S. 1998. The Boquira lead-zinc mine in Central Bahia, Brazil. In: Depósitos Minerais Brasileiros de Metais-Base, Workshop, Extended Abstracts, 38-47.

Fortes P.T.F.O, Giuliani G., Coelho R.F. 1995. Estudo de inclusões fluidas de minérios dos depósitos auríferos Mina III e Mina Inglesa, greenstonebelt de Crixás, GO. Revista da Escola de Minas, Ouro Preto., 49(2):131-135.

Fortes P.T.F.O. 1997. Metalogenia e potencial aurífero dos greenstonebelts de Crixás, Guarinos e Pilar de Goiás, GO. Relatório ao CNPq. Inédito, 8 p.
Fraenkel M.O., Santos R.C., Loureiro F.E.V.P., Muniz W.S. 1985. Jazida de urânio no Planalto de Poços de Caldas, Minas Gerais. Principais Depósitos Minerais Brasileiros - Recursos Minerais Energéticos. DNPM, Vol. 1, 89-103.

Freitas-Silva F.H. \& Dardenne M.A. 1997. Pb/Pb isotopic patterns of galenas from Morro do Ouro (Paracatu Formation), Morro Agudo (Vazante Formation) and Bambui Group deposits. In: SSAGI-South-American Symposium on Isotope Geology, Resumos Expandidos, 118-120.

Freitas-Silva F.H. 1998. Controle estrutural da mineralização aurífera de Serra Pelada, Curionópolis - PA. In: SBG, Congresso Brasileiro de Geologia, 40, Belo Horizonte, Anais, Resumos, 131

Galvão C.F., Vianna I.A., Nonato I.F.B.P., Brito R.S.C. 1986. Depósito de magnetita vanadinífera da Fazenda Gulçari, Maracás, Bahia. In '.Principais Depósitos Minerais Brasileiros - Ferro e Metais da Indústria do Aço. DNPM, Vol. 2,493-501.

Gierth E. \& Baecker M.L. 1986. A mineralização de nióbio e as rochas alcalinas associadas no Complexo de Catalão I, Goiás. In '.Principais Depósitos Minerais Brasileiros Ferro e Metais da Indústria do Aço. DNPM, Vol. 2, 455-462.

GITEW/SUMEN-CVRD 1988. Jazida de ouro da Fazenda Maria Preta, Santa Luz, Bahia In: Schobbenhaus, C., Coelho, C.E.S. (Eds.), 1988. Principais Depósitos Minerais Brasileiros - Metais Básicos Não Ferrosos, Ouro e Alumínio. DNPM, Vol. 3 , 445-461.

Giuliani G. \& D'E1 Rey Silva L.J.H., Couto P. 1990. Origin of emerald deposits of Brazil. Mineralium Deposita, 25:57-64.

Giuliani G., Cheilletz A, Féraud G., Zimmermann J-L., Carillo V., Rueda F., Baker J., Montigny R. 1994. Age of sulphur isotope signatures of brazilian and colombian emeralds. In: Congreso Geológico Chileno, 7 (Concepcion), Actas, 2:1491-1495.

Giuliani G., Zimmermann J.-L., Montigny R. 1994. K-Ar and 40Ar/39Ar evidence for Transamazonian age (2030-1970 Ma) for granites and emerald-bearing K-metasomatites from Campo formoso and Carnaíba (Bahia, Brazil,). Journal of South American Earth Sciences, 2:149-165.

Gomes J.C.M., 1986. As minas de Águas Claras, Mutuca e Picos e outros depósitos de minério de ferro do Quadrilátero Ferrífero, Minas Gerais. In Principais Depósitos Minerais Brasileiros - Ferro e Metais da Indústria do Aço. DNPM, Vol. 2, 65-75.

Gonzaga G.M. \& Tompkins L.A. 1991. Geologia do diamante. Principais Depósitos Minerais Brasileiros - Gemas e Rochas Ornamentais. DNPM, Vol. 4, 53-116.

Guimarães P.F., Massahud J.S., Viveiros J.F.M. 1986. A mina de ferro de Capanema, na parte central do Quadrilátero Ferrífero, Minas Gerais. In '.Principais Depósitos Minerais Brasileiros-Ferro e Metais da Indústria do Aço. DNPM, Vol. 2, 97-101.

Haraly N.L.E. \& Walde D.H.G. 1986. Os minérios de ferro e manganês da região de Urucum, Corumbá, Mato Grosso do Sul. In Principais Depósitos Minerais Brasileiros - Ferro e Metais da Indústria do Aço. DNPM, Vol. 2, 127-144.

Haraly N.L.E. 1991. Os diamantes de Juína, Mato Grosso. Principais Depósitos Minerais Brasileiros - Gemas e Rochas Ornamentais. DNPM, Vol. 4, 155-160.

Hassano S. 1985. Jazida de urânio de Amorinópolis, Goiás. Principais Depósitos Minerais Brasileiros - Recursos Minerais Energéticos. DNPM, Vol. 1, 157-167.

Hasui Y. \& Cordani U.G. 1962. Idade K-Ar de rochas eruptivas mesozóicas do oeste mineiro e sul de Goiás. In: SBG, Congresso Brasileiro de Geologia, 22, Rio de Janeiro, Anais, 1:139-143.

Heim S.L. \& Castro Filho L.W. 1986. Jazida de níquel laterítico de Puma-Onça, Município de São Felix do Xingu, Pará. In Principais Depósitos Minerais Brasileiros - Ferro e Metais da Indústria do Aço. DNPM, Vol. 2, 347-368.

Hernalsteens C.M.O. \& Lapa R.P. 1988. Bauxita de Porto Trombetas, Oriximiná, Pará. In: SchobbenhausC., Coelho C.E.S. (Eds.), 1988. Principais Depósitos Minerais Brasileiros - Metais Básicos Não Ferrosos, Ouro e Alumínio. DNPM, Vol. 3 , 622-639

Horbach R. \& Marimon R.G. 1980. Esboço da evolução tectônica e seu significado na génese dos depósitos de fluorita do sudeste catarinense. In: SBG, Congresso Brasileiro de Geologia, 31, Camboriu, Anais, 3:1540-1551.

Horbach R. \& Marinon M.P.C. 1988. Depósito de cobre do Serrote da Laje, Arapiraca, Alagoas, Principais Depósitos Minerais Brasileiros - Metais Básicos Não Ferrosos, Ouro e Alumínio. DNPM, Vol. 3, 61-70.

Issler R.S. \& Silva G.G. 1980. The Seis Lagos carbonatite complex. In: SBG, Congresso Brasileiro de Geologia, 31, Camboriu, Anais, 3:1564-1573.

lyer S.S., Hoefs J., Krouse H.R. 1992. Sulfur and lead isotope geochemistry of galenas from the Bambui Group, Minas Gerais, Brazil - Implications for ore génesis. Economic Geology, 87:437-443.

Junchen P.L., Hofmeister T., Brum T.M.M. 1990. Substâncias gemológicas do Rio Grande do Sul - Modos de ocorrência e caracterização gemológica. In: SBG, Congresso Brasileiro de Geologia, 36, Natal, Anais, 3:1436-1449

Justo L.J.E.C. \& Souza M.M. 1986. Jazida de nióbio do Morro dos Seis Lagos, Amazonas. In 'Principais Depósitos Minerais Brasileiros - Ferro e Metais da Indústria do Aço. DNPM, Vol. 2,463-468.

Kotschoubey B. 1988. Geologia do alumínio. In: Schobbenhaus, C., Coelho, C.E.S. (Eds.), 1988. Principais Depósitos Minerais Brasileiros - Metais Básicos Não Ferrosos, Ouro e Aluminio. DNPM, Vol. 3, 599-619.

Kuyumjian R.M. 1990. As zonas de alteração associadas ao depósito de Cu-Au de Chapada, Goiás, Brasil. . In: SBG, Congresso Brasileiro de Geologia, 36, Natal, Anais, 3:1172-1178.

Kuyumjian R.M. 1998. The magmatic are of western Goiás: A promising exploration target. . In: Depósitos Minerais Brasileiros de Metais-Base, Workshop, Extended Abstracts, 80-85.

Ladeira E.A. 1988. Metalogenia dos depósitos de ouro do Quadrilátero Ferrífero, Minas Gerais. In: Schobbenhaus, C., Coelho, C.E.S. (Eds.), 1988. Principais Depósitos Minerais Brasileiros - Metais Básicos Não Ferrosos, Ouro e Alumínio. DNPM, Vol. 3, 301-376.

Leach D.L. \& Sangster D.F. 1993. Mississippi Valley-type lead-zinc deposits. In: Kirkham, R.V., Sinclair, W.D.,Thorpe, R.I., Duke, J.M. (eds.) "Mineral Deposit Modeling" , Special Paper n ${ }^{\circ}$ 40, Geol. Assoe. Canada, 289-314.

Leinz V. 1940. Petrologia dasjazidas de apatita de Ipanema-SP. Ministério da Agricultura Serviço de Publicidade Agrícola, Boletim n ${ }^{\circ} 40,52 \mathrm{p}$.

Lima e Silva F.J., Cavalcante P.R.B., Sá E.P., D'E1 Rey Silva L.J.H., Machado J.C.M. 1988. Depósito de cobre de Caraíba e o Distrito Cuprífero do Vale do Rio Curaça, Bahia. Principais Depósitos Minerais Brasileiros - Metais Básicos Não Ferrosos, Ouro e Alumínio. DNPM, Vol. 3, 11-31. 
Lindenmayer Z.G. 1998. O depósito de Cu (Au-Mo) do Salobo, Serra dos Carajás, revisitado. In: Depósitos Minerais Brasileiros de Metais-Base, Workshop, Extended Abstracts, 29-36.

Lopes R.F. \& Branquinho J. A. 1988. Jazidas de bauxita da zona da Mata de Minas Gerais. In: Schobbenhaus, C., Coelho, C.E.S. (Eds.), 1988. Principais Depósitos Minerais Brasileiros - Metais Básicos Não Ferrosos, Ouro e Alumínio. DNPM, Vol. 3 , 655-659.

Macambira J.B., MacambiraM.J.B., ChellerT., Gomes A.K.B. 1996. Geocronologia Pb/Pb e tipologia de zircões de rochas vulcânicas da Formação Carajás - Pará, indicador da idade dos BIFs. In: SBG, Congresso Brasileiro de Geologia, 39, Camboriu, Anais, 6:516-519.

Macambira M.J.B., Hartmann L.A, Dall'Agnol R., Chemale L. 1996. Zircão e granitogênese, resultados preliminares para os granitoides de Rio Maria, Província de Carajás - Pará. In: SBG, Congresso Brasileiro de Geologia, 39, Camboriu, Anais, 6:411-414.

Machado N., Schrank A, Noce C.M., Gauthier G. 1996. Idades de zircões detríticos de sequências arqueanas e paleoproterozóicas do Quadrilátero Ferrífero - Implicações para a evolução do greenstonebelt do Rio das Velhas e da bacia de foreland do Supergrupo Minas. In: SBG, Congresso Brasileiro de Geologia, 39, Camboriu, Anais, 6:110-113.

Magalhães L.F., Lobo R.L.M., Botelho L.C. A., Pereira R.C. 1988. Depósito de ouro de Meia Pataca, Crixás, Goiás In: Schobbenhaus, C. , Coelho, C.E.S. (Eds.), 1988. Principais Depósitos Minerais Brasileiros - Metais Básicos Não Ferrosos, Ouro e Alumínio. DNPM, Vol. 3, 499-522.

Maranhão R., Barreiro D.S., Silva A.P., Lima F., Pires P.R.R. 1986. Jazida de scheelita de Brejui, Barra Verde, Boca de Lage, Zangarelhas, Rio Grande do Norte. In :Principais Depósitos Minerais Brasileiros - Ferro e Metais da Indústria do Aço. DNPM, Vol. 2, 393-407.

Marchetto C.M.L. 1986. Platinóides associados ao minério de níquel, cobre e cobalto de Fortaleza de Minas - MG. In: SBG, Congresso Brasileiro de Geologia, 34, Goiânia, Anais, 4:1589-1603.

Marimom M.P.C, Kishida A, Teixeira J.B.G. 1986. Estudo da alteração hidrotermal relacionada à mineralização aurífera da Fazenda Brasileiro - BA.. In: SBG, Congresso Brasileiro de Geologia, 34, Goiânia, Anais, 4:1556-1570.

Medeiros Neto F.A. \& Villas R.N.N. 1985. Geologia da jazida de Cu-Zn do corpo 4E-Pojuca, Serra dos Carajás. In: Simpósio de Geologia da Amazônia, 2, Anais, $97-112$.

Medeiros Neto F. A. 1986 a. Mineralizações auríferas da área Pojuca: estração, transporte e deposição a partir de fluidos hidrotermais salinos. In: SBG, Congresso Brasileiro de Geologia, 34, Goiânia, Anais, 5:1969-1981.

Medeiros Neto F. A. 1986 b. Zoneamento químico e mineralógico da jazida Pojuca, Serra dos Carajás: Ferramentas potenciais na exploração mineral. In: SBG, Congresso Brasileiro de Geologia, 34, Goiânia, Anais, 4:1541-1555.

Meireles E.M. \& Silva A.R.B. 1988. Depósito de ouro de Serra Pelada, Marabá, Pará. In: Schobbenhaus C. , Coelho C.E.S. (Eds.), 1988. Principais Depósitos Minerais Brasileiros - Metais Básicos Não Ferrosos, Ouro e Alumínio. DNPM, Vol. 3, 547-557.

Mellito K.M. \& Tassinari C.C.G. 1998. Aplicação dos métodos Rb-Sr e Pb-Pb à evolução da mineralização cuprífera do depósito de Salobo 3 , Província Mineral de Carajás, Pará. In: SBG, Congresso Brasileiro de Geologia, 40, Belo Horizonte, Anais, Resumos, 119.

Mello C.H.M.P., Durão G., Viana J.S., Carvalho C.J.C. 1986. Depósitos de cromita das Fazendas Medrado e Ipueiras, Município de Senhor do Bonfim, Bahia. In :Principais Depósitos Minerais Brasileiros - Ferro e Metais da Indústria do Aço. DNPM, Vol. 2, 215-234

Mello E.F., Assis C.M., Orlandi P.H., Costa H.C., Albuquerque R., Silva, G.L.P., Xavier R.P. 1996. Contribuição à tipologia dos veios auríferos da Mina Fazenda Brasileiro, greenstone belt do Rio Itapicuru, BA. In: SBG, Congresso Brasileiro de Geologia, 39, Camboriu, Anais, 3:238-241.

Melo M.T.V., Borba R.R., Coelho W.A. 1986. O distrito Ferrífero de Itabira: Minas do Cauê, Conceição, Dois Córregos, Piriquito, Onça, Chacrinha e Esmeril. In :Principais Depósitos Minerais Brasileiros - Ferro e Metais da Indústria do Aço. DNPM, Vol. 2, 7-28.

Mendonç J.C.G.S. Campos M., Braga A.P.G., Souza E.M., Favali J.C., Leal J.R.L. 1985. Jaaida de urânio de Itataia, Ceará. Principais Depósitos Minerais Brasileiros Recursos Minerais Energéticos. DNPM, Vol. 1,121-131.

Misi A. \& Silva G.M. 1996. Chapada Diamantina Oriental - Bahia: Geologia e Depósitos Minerais. Série Roteiros Geológicos. SGM-Superintendência de Geologia e Recursos Minerais, Governo da Bahia, 194p.

Misi A., lyer S.S., Tassinari C.C.G., Coelho C.E.S., Kyle J.R. 1998. Integrated studies and metallogenic evolution of the proterozoic sediment-hosted $\mathrm{Pb}-\mathrm{Zn}-\mathrm{Ag}$ sulfide deposits of the São Francisco Craton, Brazil. In: Depósitos Minerais Brasileiros de Metais-Base, Workshop, Extended Abstracts, 94-101

Molinari L. \& Scarpelli W. 1988. Depósitos de ouro de Jacobina, Bahia. In: Schobbenhaus C., Coelho C.E.S. (Eds.), 1988. Principais Depósitos Minerais Brasileiros - Metais Básicos Não Ferrosos, Ouro e Alumínio. DNPM, Vol. 3, 463-489.

Monteiro H., Macedo P.M., Moraes A. A.., Marchetto C.M.L., Fanton J.J.F., Magalhães C.C. 1988. Depósito de ouro de Cabaçal I, Mato Grosso. In: Schobbenhaus, C. Coelho, C.E.S. (Eds.), 1988. Principais Depósitos Minerais Brasileiros - Metais Básicos Não Ferrosos, Ouro e Alumínio. DNPM, Vol. 3,535-545.

Morrone N. \& Daemon R.F., 1985. Jazida de urânio de Figueira, Paraná. Principais Depósitos Minerais Brasileiros - Recursos Minerais Energéticos. DNPM, Vol. 1, 133-142.

Mougeot R., Respaut J.P., Briqueu L., Ledru P., Macambira M.J.B., Huhn S.B. 1996. Geochronological constrains for the age of the Aguas Claras Formation (Carajás Province, Para, Brazil). In: SBG, Congresso Brasileiro de Geologia, 39, Camboriu, Anais, 6:579-581

Mougeot R., Respaut J.P., Ledru P., Milesei J.P., Johan V. 1996. U-Pb geochronological constrains for the evolution of paleoproterozoic Jacobina auriferous basin (São Francisco Province, Bahia, Brazil). In: SBG, Congresso Brasileiro de Geologia, 39, Camboriu, Anais, 6:582-584 Moura M. A. \& Botelho N.F. 1998. A mineralização do tipo pórfiro de Serrinha (Matupá,

MT). In: SBG, Congresso Brasileiro de Geologia, 40, Belo Horizonte, Anais, Resumos, 116.

Nalini Jr. H.A., Bilal E., Correia Neves J.M., Carneiro M.A. 1996. Geoquímica e idades $\mathrm{U}-\mathrm{Th}-\mathrm{Pb}$ de monazitas dos leucogranitos da suíte Urucum, Médio Rio Doce, Minas Gerais. In: SBG, Congresso Brasileiro de Geologia, 39, Camboriu, Anais, 6:415-417.

Nilson A.A., Santos M.M., Cuba E.A., Gomes de Sá C.M. 1986. Jazida de níquel, cobre e cobalto de Americano do Brasil, Goiás. In -.Principais Depósitos Minerais Brasileiros - Ferro e Metais da Indústria do Aço. DNPM, Vol. 2, 258-273.

Oliveira A.G., Fuzikawa K., Moura L.A.M., Raposo C. 1985. Província uranífera de Lagoa Real, Bahia. Principais Depósitos Minerais Brasileiros - Recursos Minerais Energéticos. DNPM, Vol. 1, 105-120.

Oliveira C.G., Tazava E., Tallarico F., Santos R.V., Gomes C. 1998. Génese do depósito de $\mathrm{Au}-\mathrm{Cu}$ (U-ETR) de Igarapé Bahia, Província Mineral de Carajás. In: SBG, Congresso Brasileiro de Geologia, 40, Belo Horizonte, Anais, Resumos, 137.

Oliveira T.F. 1998. As minas de Vazante e de Morro Agudo, Minas Gerais. In: Depósitos Minerais Brasileiros de Metais-Base, Workshop, Extended Abstracts, 48-57.

Palermo N. 1996. Le gisement aurifére Précambrien de Posse (Goiás, Brésil) dans son cadre géologique. L'École Nationale Supérieurede Mines de Paris, Doutorado, 340 $\mathrm{P}-$

Parisi C.A. 1988. Jazidas de bauxita da região de Poços de Caldas, Minas Gerais - São Paulo. In: Schobbenhaus C., Coelho C.E.S. (Eds.), 1988. Principais Depósitos Minerais Brasileiros - Metais Básicos Não Ferrosos, Ouro e Alumínio. DNPM, Vol. 3, 661-666.

Parisi C.A. 1988. Jazidas de bauxita de Morro Redondo, Resende, Rio de Janeiro. In: Schobbenhaus, C. , Coelho, C.E.S. (Eds.), 1988. Principais Depósitos Minerais Brasileiros - Metais Básicos Não Ferrosos, Ouro e Alumínio. DNPM, Vol. 3, 667-670.

Pedroso A.C. \& Schmaltz W.H. 1986. Jazimentos de níquel laterítico de Niquelândia, Goiás. In -Principais Depósitos Minerais Brasileiros - Ferro e Metais da Indústria do Aço. DNPM, Vol. 2, 307-314

Pimentel M.M. \& Fuck R.A., 1992. Neoproterozoic crustal accretion in central Brazil. Geology, 20:375-379.

Remus M.V.D., McNaughton N.J., Hartmann L.A, Groves D.I., Reischl J.L.. 1997. Pb and $\mathrm{S}$ isotope signature of sulphides and constraints on timing and soureces of $\mathrm{Cu}(\mathrm{Au})$ mineralisation at Camaquã and Santa Maria Mines, Caçapava do Sul, southern Brazil. In: SSAGI-South-American Symposium on Isotope Geology, Resumos Expandidos, 253-255.

Réquia K.C.M. \& Xavier R.P. 1995. Fases fluidas na evolução metamórfica do depósito polimetálico de Salobo, Província Mineral de Carajás, Pari Revista da Escola de Minas, Ouro Preto, 49(2): 117-122.

Richardson S. V., Kesler S.E., Essene E.J. 1986. Origin and evolution of the Chapada Cu-Au deposit, Goiás, Brazil: A metamorphosed wall-rock porphyry copper deposit. Economic Geology, 81:1884-1898.

Rigobello A.E., Branquinho J.A., Dantas M.G.S., Oliveira T.F., Nieves Filho W. 1988. Mina de zinco de Vazantes, Minas Gerais. Principais Depósitos Minerais Brasileiros - Metais Básicos Não Ferrosos, Ouro e Alumínio. DNPM, Vol. 3 , 101-110.

Roberto F.A.C. \& Souza V.C. 1991. Depósitos de opala de Pedro H, Piaui. Principais Depósitos Minerais Brasileiros - Gemas e Rochas Ornamentais. DNPM, Vol. 4 , 337-346.

Rodrigues A.F.S. 1991. Topázio de Massangana (Rondônia): aspectos geológicos, gemológicos e econômicos. Principais Depósitos Minerais Brasileiros - Gemas e Rochas Ornamentais. DNPM, Vol. 4, 309-319.

Rodrigues A.S.S. 1991. Depósitos diamantíferos de Roraima. Principais Depósitos Minerais Brasileiros - Gemas e Rochas Ornamentais. DNPM, Vol. 4, 177-199.

Rodrigues O.B.., Kosuki R., Coelho Filho A. 1986. Distrito manganesífero de Serra do Navio, Amapá. In: Principais Depósitos Minerais Brasileiros - Ferro e Metais da Indústria do Aço. DNPM, Vol. 2, 167-175.

Romagna G. \& Costa R.R. 1988. Jazida de chumbo e zinco de Morro Agudo, Paracatu, Minas Gerais. Principais Depósitos Minerais Brasileiros - Metais Básicos Não Ferrosos, Ouro e Alumínio. DNPM, Vol. 3, 111-121.

Ronchi L.H. \& Lindenmayer Z.G. 1998. Ruídos hidrotermais das intrusões granofiricas da mina de Au do Igarapé Bahia e do depósito ferrífero de S11, Serra Sul, Serra dos Carajás, Pará. In: SBG, Congresso Brasileiro de Geologia, 40, Belo Horizonte, Anais, Resumos, 171

Ronchi L.H., Touray J.C., Dardenne M.A. 1995. Inclusões fluidas primárias em relação ao último evento de circulação de fluidos: Caso das fluoritas dos depósitos estratóides do Vale do Ribeira - PR Revista da Escola de Minas-Ouro Preto 49(2): 102-110.

Ruberti E., Castorina F., Censi P., Gomes C.B., Speziale S , Comin-Chiaramonti P. 1997. REE-0-C-Sr-Nd systematics in carbonatites from Barra do Itapirapuã and Mato Preto (southern Brazil). In: SSAGI-South American Symposium on Isotope Geology, Extended Abstracts, 271-275.

Ruberti E., Marguti R.L., Gomes C.B. 1991. O complexo Carbonatítico de Jacupiranga, SP: Informações gerais. In: Congresso Brasileiro de Geoquímica, 3, Guias de Excursões, 1-20.

Salim J., Legrand J.M., Verkaeren J. 1996. Mobilidade de elementos químicos durante a formação dos skarns a scheelita da Mina Brejui, Currais Novos (RN). In: SBG, Congresso Brasileiro de Geologia, 39, Camboriu, Anais, 6:272-276.

Sampaio D.R., Lima R.F.F., Moreira J.F.C. 1986. Os depósitos de ferro, titânio e vanádio de Campo Alegre de Lourdes, Bahia. In :Principais Depósitos Minerais Brasileiros - Ferro e Metais da Indústria do Aço. DNPM, Vol. 2,481-491.

Santos J.F. 1986. Depósito de níquel de São João do Piauí, Piauí. In -.Principais Depósitos Minerais Brasileiros - Ferro e Metais da Indústria do Aço. DNPM, Vol. 2,341 -345.

Santos J.O.S., Hartmann L.A, Gaudette, H.E. 1997. Reconnaissance U/Pb in zircon, $\mathrm{Pb} / \mathrm{Pb}$ in sulfides and review of $\mathrm{Rb} / \mathrm{Sr}$ geochronology in the Tapajós gold province, Pará, Amazonas State, Brazil. In: SSAGI-South American Symposium on Isotope Geology, Extended Abstracts, 280-282.

Santos L.C.S. \& Anacleto R. 1985. Jazida de urânio de Espinharas, Paraíba. Principais Depósitos Minerais Brasileiros - Recursos Minerais Energéticos. DNPM, Vol. 1, 143-155. 
Santos O.M., Victorasso E.C.L., da Silva R.M., Gerra H.R.M., Chaves J.L., Mantovani T.J., Albuquerque e Silva R., Kalil Jr. A.R., Santos V.A.M., Navarro L.A.G., Pena L.S.T., 1988. Mina de ouro da Fazenda Brasileiro. In: Schobbenhaus, C., Coelho, C.E.S. (Eds.), 1988. Principais Depósitos Minerais Brasileiros - Metais Básicos Não Ferrosos, Ouro e Aluminio. DNPM, Vol. 3,431-444.

Schmitt J.C.C., Camatti C., Barcellos R.C. 1981. Depósitos de ametista e ágata no Estado do Rio Grande do Sul. Principais Depósitos Minerais Brasileiros - Gemas e Rochas Ornamentais. DNPM, Vol. 4, 271-285.

Schobbenhaus C. \& Campos D.A . 1984. A evolução da Plataforma Sul-Americana no Brasil e suas principais concentrações minerais. In: Schobbenhaus, C., Campos, D.a , Derze, G.R., Asmus, H.E (Coord.) Geologia do Brasil-Texto Explicativo do Mapa Geológico do Brasil 1:2.500.000. DNPM-MME, $501 \mathrm{p}$.

Schobbenhaus C. \& Coelho C.E.S. (Eds.), 1986. Principais Depósitos Minerais Brasileiros - Ferro e Metais da Indústria do Aço. DNPM, Vol. 2, 501 p.

Schobbenhaus C. \& Coelho C.E.S. (Eds.), 1992. Principais Depósitos Minerais Brasileiros - Gemas e Pedras Preciosas. DNPM, Vol. 4, 423 p.

Schobbenhaus C. \& Coelho C.E.S. (Eds.), 1988. Principais Depósitos Minerais Brasileiros - Metais Básicos Não Ferrosos, Ouro e Alumínio. DNPM, Vol. 3, 670 p.

Schobbenhaus C. (Ed.), 1985. Principais Depósitos Minerais Brasileiros - Recursos Minerais Energéticos., DNPM, Vol. 1, 187 p.

Schobbenhaus C. 1986. Geologia do níquel. . Principais Depósitos Minerais Brasileiros - Ferro e Metais da Indústria do Aço. DNPM, Vol. 2, 251-255.

Schrank A. \& Machado N. 1996 a. Idades U-Pb em monazitas e zircões das Minas de Morro Velho e Passagem de Mariana - Quadrilátero Ferrífero (MG). In: SBG, Congresso Brasileiro de Geologia, 39, Camboriu, Anais, 6:470-472.

Schrank A. \& Machado N. 1996 b. Idades U-Pb em monazitas e zircões do Distrito Aurífero de Caeté, da mina de Cuiabá e do depósito de Carrapato - Quadrilátero Ferrífero (MG). In: SBG, Congresso Brasileiro de Geologia 39, Camboriu, Anais, 6:473-475.

Schwarz D. 1986. Classificação genética das ocorrências de esmeralda. In: SBG, Congresso Brasileiro de Geologia, 34, Goiânia, Anais, 4:1854-Castro, N. A. 1997.

Seer H.J. 1985. Geologia, deformação e mineralização de cobre no complexo vulcano-sedimentar de Bom Jardim de Goiás. Instituto de Geociências, UnB, Tese M.Sc., 230 p.

Silva A.R.B. \& Cordeiro A.A.C. 1988. Depósito de ouro da Serra das Andorinhas, Rio Maria, Pará. In: Schobbenhaus C. , Coelho C.E.S. (Eds.), 1988. Principai Depósitos Minerais Brasileiros - Metais Básicos Não Ferrosos, Ouro e Alumínio. DNPM, Vol. 3, 559-567.

Silva B.C.E. \& da Silva E. A., 1981. Água marinha na Bahia. Principais Depósitos Minerais Brasileiros - Gemas e Rochas Ornamentais. DNPM, Vol. 4, 321-326.

Silva G.M. \& Misi A. 1998. Embasamento Arqueano-Proterozóico Inferior do Cráton do São Francisco no Nordeste da Bahia - Depósitos Minerais. Série Roteiros Geológicos. SGM-Superintendência de Geologia e Recursos Minerais, Governo da Bahia, $164 \mathrm{p}$.

Silva J.A. \& Sá J.A.G. 1988. Jazida de cobre de Chapada, Mara Rosa, Goiás. Principais Depósitos Minerais Brasileiros - Metais Básicos Não Ferrosos, Ouro e Alumínio. DNPM, Vol. 3,55-60.

Souza J.L. 1991. A jazida de esmeralda de Itabira, Minas Gerais. Principais Depósitos Minerais Brasileiros - Gemas e Rochas Ornamentais. DNPM, Vol. 4, 223-243.

Souza N.B. 1991. Depósitos diamantíferos de Poxoréu, Mato Grosso. Principais Depósitos Minerais Brasileiros - Gemas e Rochas Ornamentais. DNPM, Vol. 4, 149-154.

Sparrenberger I. \& Tassinari C.C.G. 1998. Idade da mineralização estanífera da Subprovíncia do Paraná (GO) através de datações U-Pb em cassiterita. In: SBG, Congresso Brasileiro de Geologia, 40, Belo Horizonte, Anais, Resumos, 143.

Tallarico F.H.B., Rego J.L., Oliveira C.G. 1998 a. A mineralização de Au-Cu de Igarapé Bahia: um depósito da classe óxido de $\mathrm{Fe}(\mathrm{Cu}-\mathrm{U}-\mathrm{Au}-\mathrm{ETR})$. In: SBG, Congresso Brasileiro de Geologia, 40, Belo Horizonte, Anais, Resumos, 116.

Tallarico F.H.B., Rego J.L., Oliveira C.G. 1998 b. Petrografia e mineralogia da sequência vulcânica encaixante da mineralização de Au-Cu de Igarapé Bahia - Carajás. In: SBG, Congresso Brasileiro de Geologia, 40, Belo Horizonte, Anais, Resumos, 157.
Tassinari C. \& Mellito K. 1994. The time-bound characteristícs of gold deposits in Brazil and their implications. Comunicaciones-Universidadde Chile, 45:45-54

Tazava E., Gomes N.S., Oliveira C.G. 1998. Significado da pirosmalita no depósito de $\mathrm{Cu}-\mathrm{Au}$ (U, ETR) de Igarapé Bahia, Província Mineral de Carajás. In: SBG, Congresso Brasileiro de Geologia, 40, Belo Horizonte, Anais, Resumos, 161.

Teixeira G. \& Gonzalez M. 1988. Minas do Camaquã, Município de Caçapava do Sul, RS. Principais Depósitos Minerais Brasileiros - Metais Básicos Não Ferrosos, Ouro e Alumínio. DNPM, Vol. 3, 33-41.

Teixeira J.B.G. 1985. Geologia e controles da mineração aurífera em Fazenda Brasileiro, Serrinha, (BA). Geologia e Recursos Minerais do Estado da Bahia - Textos Básicos, 6:9-50.

Tempkins L. A. \& Gonzaga G.M. 1989. Diamonds in Brazil and a proposed model for the origin and distribution of diamonds in the Coromandel region, Minas Gerais, Brazil. Economic Geology, 84:591-602.

Tosdal R.M., Bettencourt J.S., Leite Jr. W.B., Payolla B.L.. 1996. U-Pb geochronology framework of the mesoproterozoic rapakive granites of the Rondônia tin province, Brazil. In: SBG, Congresso Brasileiro de Geologia, 39, Camboriu, Anais, 6:591-584.

Vasconcelos J. A., Santana F.C., Polónia J.C. 1986. Minério de ferro de Timbopeba, Minas Gerais. In :Principais Depósitos Minerais Brasileiros - Ferro e Metais da Indústria do Aço. DNPM, Vol. 2, 103-110.

Veiga A.T.C. 1988 (a). Mina de ouro de Novo Planeta, Alta Floresta, Mato Grosso. In: Schobbenhaus, C. , Coelho, C.E.S. (Eds.), 1988. Principais Depósitos Minerais Brasileiros - Metais Básicos Não Ferrosos, Ouro e Alumínio. DNPM, Vol. 3, 569-574.

Veiga A.T.C. 1988 (b). As minas de estanho de Igarapé Preto - Amazonas, MassanganaRondônia e São Francisco - Mato Grosso, Província Estanífera da Rondônia. Principais Depósitos Minerais Brasileiros-Metais Básicos Não Ferrosos, Ouro e Aluminio. DNPM, Vol. 3, 255-260.

Vilela O. V. 1986. As jazidas de minério de ferro dos Municípios de Porteirinha, Rio Pardo de Minas, Riacho dos Machados e Grão-Mongol, norte de Minas Gerais. In :Principais Depósitos Minerais Brasileiros - Ferro e Metais da Indústria do Aço. DNPM, Vol. 2, 111-120.

Villaça J.N. \& Moura L.A.M. 1985. O urânio e o ouro da Formação Moeda, Minas Gerais. Principais Depósitos Minerais Brasileiros - Recursos Minerais Energéticos. DNPM, Vol. 1,177-187.

Xavier R., FosterR., Fallick A, AldertonD. 1994. Potential fluid reservoir for mesotherma gold deposits in the rio Itapicuru greenstone belt, Bahia, Brazil. Comunicaciones, Universidad de Chile, 45:13-22.

Yamaoka W.N. \&, Araújo E.M. 1988. Depósito de ouro da "Mina" III, Crixás, Goiás. In: Schobbenhaus C. , Coelho C.E.S. (Eds.), 1988. Principais Depósitos Minerais Brasileiros - Metais Básicos Não Ferrosos, Ouro e Alumínio. DNPM, Vol. 3 , 491-498.

Zacarelli M. A. 1988. Mina de Chumbo de Panelas, Paraná. Principais Depósitos Minerais Brasileiros - Metais Básicos Não Ferrosos, Ouro e Alumínio. DNPM, Vol. 3 , 147-156.

Zini A., Forlim R., Andreazza P., Souza A. 1988. Depósito de ouro do Morro do Ouro, Paracatu, Minas Gerais. In: Schobbenhaus, C., Coelho, C.E.S. (Eds.), 1988. Principais Depósitos Minerais Brasileiros - Metais Básicos Não Ferrosos, Ouro e Alumínio. DNPM, Vol. 3, 479-489. 